\title{
Article \\ Profiling of Phenolic Compounds Composition, Morphological Traits, and Antioxidant Activity of Miscanthus sacchariflorus L. Accessions
}

\author{
Bimal Kumar Ghimire ${ }^{1}$, Erik J. Sacks ${ }^{2} \mathbb{D}$, Seung Hyun Kim ${ }^{1}$, Chang Yeon $\mathrm{Yu}^{3}$ and Ill Min Chung ${ }^{1, *}$ \\ 1 Department of Crop Science, College of Sanghuh Life Science, Konkuk University, Seoul 05029, Korea; \\ bimalg12@konkuk.ac.kr (B.K.G.); kshkim@konkuk.ac.kr (S.H.K.) \\ 2 Department of Crop Science, University of Illinois, Urban-Champaign, 1201 W, Gregory Dr., \\ Urbana, IL 61801, USA; esacks@illinois.edu \\ 3 Interdisciplinary Program in Smart Science, Kangwon National University, Chuncheon 200-701, Korea; \\ cyyu@kangwon.ac.kr \\ * Correspondence: imcim@konkuk.ac.kr
}

Citation: Ghimire, B.K.; Sacks, E.J.; Kim, S.H.; Yu, C.Y.; Chung, I.M. Profiling of Phenolic Compounds Composition, Morphological Traits, and Antioxidant Activity of Miscanthus sacchariflorus L. Accessions. Agronomy 2021, 11, 243. https:// doi.org/10.3390/agronomy11020243

Academic Editor:

Antonios Chrysargyris

Received: 11 December 2020

Accepted: 22 January 2021

Published: 28 January 2021

Publisher's Note: MDPI stays neutral with regard to jurisdictional claims in published maps and institutional affiliations.

Copyright: (c) 2021 by the authors. Licensee MDPI, Basel, Switzerland. This article is an open access article distributed under the terms and conditions of the Creative Commons Attribution (CC BY) license (https:// creativecommons.org/licenses/by/ $4.0 /)$.
Abstract: Miscanthus sacchariflorus is a potential source of sustainable biofuel and other bioactive compounds. The high adaptive range of $M$. sacchariflorus may cause variation in its morphological traits and phytochemical composition. Although some metabolites have been reported from M. sacchariflorus, little is known about its phenolic compound composition and antioxidant or oxidant properties. This study evaluated the morphological traits, antioxidant properties, and phenolic compound profile of $M$. sacchariflorus collected from various regions of China, Korea, Japan, and Russia. The antioxidant potential of the leaf extracts of various accessions of $M$. sacchariflorus was estimated by 1,1-diphenyl-2-picrylhydrazyl (DPPH) radical scavenging assay and 2,2'-azinobis 3ethylbenzothiazoline-6-sulfonate (ABTS). An extensive study of the antioxidant activity and phenolic compounds of $M$. sacchariflorus obtained from different locations in four different countries could provide a comprehensive catalogue of the phytoconstituents and antioxidant properties of $M$. sacchariflorus accessions to consumers and nutraceutical industries. A total of 22 phenolic compounds were identified and quantified, among which $p$-coumaric acid, ferulic acid, $p$-hydroxybenzoic acid, chlorogenic acid, vitexin, and luteolin were the most dominant phytochemical compounds detected in the majority of the accessions. The antioxidant potential (DPPH) of the leaf extracts of all of the accessions ranged from $28.85 \pm 1.53 \mu \mathrm{g} \mathrm{mL}^{-1}$ in MS-447 to $99.25 \pm 1.63 \mu \mathrm{g} \mathrm{mL}{ }^{-1}$ in MS-190. The antioxidant properties (ABTS) of the leaf extracts of all accessions ranged from $25.65 \pm 2.06$ in MS-258 to $83.62 \pm 2.02$ in MS-271. Pearson's correlation analysis showed a significant and positive correlation between antioxidant activity and total phenolic content, and total flavonoid content varied widely among M. sacchariflorus accessions from the four geographical study regions. A strong and positive association was observed between DPPH with total phenolic content and total flavonoid content. Moderately positive correlations were observed between DPPH scavenging activity with gentisic acid, $p$-hydroxybenzoic acid, chlorogenic acid, $p$-coumaric acid, rutin, and quercetin $(r=0.385, r=0.379$, $r=0.362, r=0.353, r=0.490$, and $r=0.372$, respectively), suggesting that phenolic compounds are major contributors to the antioxidant potential of $M$. sacchariflorus. Thirty-two accessions collected from four different countries (China, Korea, Japan, and Russia) were characterized for 17 quantitative morphological traits. A wide range of diversity was observed in the morphological traits, with plant height ranging from $18.00 \pm 1.00 \mathrm{~cm}$ to $163.20 \pm 4.00 \mathrm{~cm}$. Plant height was significantly correlated with biomass yield (fresh weight; $r=0.439, p<0.05$ ) and also had moderately positive correlations with culm length $(r=0.356, p<0.05)$. Culm length was moderately correlated with the biomass yield fresh weight $\left(r=0.419^{*}, p<0.05\right)$ and the biomass yield dry weight $\left(r=0.425^{*}, p<0.05\right)$; however, it exhibited weak and negative correlations with compressed plant circumference (CCirc) $(r=-0.374$, $p<0.05)$ and total culm node number $(\mathrm{TCmN})(r=-0.440, p<0.05)$. Principal components analysis was performed to assess the variation in 17 morphological traits in 32 accessions of $M$. sacchariflorus. The first two principal components explained $51.24 \%$ of the morphological variations. A dendrogram generated from unweighted pair group method with arithmetic mean (UPGMA) clustering based 
on morphological characters was not found to be consistent with another dendrogram based on phytochemicals. In both cases, the number of studied accessions collected from different geographical regions grouped into two major groups. However, no clear correlation between these two different approaches was found. The substantial variation in the morphological traits, bioactive properties, and phenolic compounds among the accessions may provide useful information for breeding programs attempting to obtain $M$. sacchariflorus varieties with improved phenolic compounds traits and improved bioactive properties.

Keywords: Miscanthus sacchariflorus; morphological traits; phytochemical; antioxidant properties

\section{Introduction}

Miscanthus sacchariflorus (Maxim.) Hack, also called Amur silver grass (Poaceae), a high C4 photosynthesis plant [1], typically propagates through clonal reproduction [2,3]. M. sacchariflorus is found primarily in the temperate regions of Asia, including India, China, Korea, Japan, and eastern Russia [4-6]. Subsequent studies have shown that $M$. sacchariflorus possesses broad environmental adaptability, as it can propagate in a variety of climatic conditions ranging from sea level to $2000 \mathrm{~m}$ altitude, in diverse soil structures, with variable water and nitrogen content, and with minimal inputs [2,3,7-13]. M. sacchariflorus typically grows in damp or wet soils near the edges of water sources, exhibits high spreading capacity due to its long rhizomes, and is considered a potential sustainable and renewable feed stock [2,3]. Some accessions of $M$. sacchariflorus are used as ornamental species, and the plant has been utilized as a source of pulp for papermaking and composite boards [14-17]. M. sacchariflorus also has significant potential to retain soil moisture and stabilize soils [18], and may have bioremedial properties [15]. It is considered an attractive candidate for bioenergy production because it produces more biomass in a year than any other capable perennial bioenergy crops, with a higher overwintering survival rate [6,19-21].

Cells generate reactive oxygen species (ROS), such as superoxidation radicals, hydroxy radicals $(\bullet \mathrm{HO})$, singlet oxygen $\left({ }^{1} \mathrm{O}_{2}\right)$, and hydrogen peroxide $\left(\mathrm{H}_{2} \mathrm{O}_{2}\right)$ during the metabolic process. The antioxidative enzymes, such as superoxide dismutase, catalase, and glutathione peroxidase present in living organisms typically effectively scavenge these reactive species. However, excessive secretion of these highly reactive species can lead to oxidative stress and degradation of the cell membrane, cell organelles, and DNA [22,23] and contribute significantly to diseases, including diabetes, cardiovascular disease, Parkinson's disease, arteriosclerosis, cancer, and aging [24-27]. Moreover, oxidation also degrades the nutritional quality of foods [28]. Antioxidants significantly delay or inhibit the oxidation of oxidizable substrates through the free radical chain mechanism [28]. Hence, the application of dietary antioxidants is important for human health and may protect foodstuffs from oxidative damage [29]. The most commonly used synthetic antioxidants are butylated hydroxy anisole, propyl gallate, and butylated hydroxy toluene, all of which are now legally regulated when administered at high concentrations because of a number of health problems, despite their excellent antioxidative properties. The development of new and safe antioxidants has therefore emerged as a very important issue.

Phenolic compounds, such as phenolic acid and flavonoids, are among the most diverse sources of natural antioxidants, are widespread among plant species, and are typically safe for consumption as dietary supplements [30-32]. Distribution of phenolic compounds varies among different accessions of a crop species, as well as within different tissues [33], and is dependent upon environmental conditions, genetics, and morphological characteristics [34]. Plants produce a wide range of phytochemicals and some soluble phenols in bioenergy crops inhibit the bioconversion of sugars to ethanol due to their toxicity to fermenting microflora [35]. Moreover, these compounds have major physiological roles in plant adaptations to different abiotic and biotic stresses [36-43]. Previous work 
on phenolic compounds in perennial Miscanthus has primarily focused on $M x$ giganteus and $M$. sinensis. No study has yet been conducted to determine the phenolic compound composition and concentrations for $M$. sacchariflorus accessions. Moreover, the antioxidant profiles of $M$. sacchariflorus accessions originating from the Korean peninsula and other countries have not been fully examined in other studies.

Characterization of morphological traits is a strong tool for assessing plant diversity owing to the relative ease of classification and taxonomic studies [44,45]. Understanding the heritability of phenotypic characters is important for the success of breeding programs [46]. However, morphological traits have limitations such as low polymorphism, late expression, and low heritability, and are prone to environmental changes [47,48]. Moreover, phenolic compounds are the building blocks of cell walls. During the biofuel production process, cellulose and hemicellulose are converted into monomers by an enzymatic hydrolysis process that utilizes various microorganisms. However, some of these phenolic compounds and their derivatives are toxic to bacteria and inhibit the enzymatic hydrolysis of lignocellulosic biomass $[49,50]$. Characterization of morphological traits and metabolite profiles is essential for the successful biomass production and industrial use of bioenergy crops [51]. M. sacchariflorus has a wide geographical range and resultant variation in nutritional value, biological activity, and agro-morphological traits. Moreover, the antioxidant profiles of M. sacchariflorus accessions originating from different parts of the Korean peninsula and other countries have not been fully examined in previous studies. Therefore, optimizing and understanding of phenolic compound composition and the morphological structure of M. sacchariflorus are crucial steps towards its use in bio fuel production.

This study evaluated the morphological traits, phenolic compound composition, and antioxidant activity of $M$. sacchariflorus collected from four different countries to select an efficient $M$. sacchariflorus genetic resource with high antioxidant value for the production of useful food ingredients or natural antioxidants. We sought to identify accessions that are rich in phenolic compounds with strong antioxidant properties. Proper preliminary profiling of the phenolic compounds and antioxidant potential in $M$. sacchariflorus may aid not only in grouping collected accessions, but may also provide baseline data for researchers working with Miscanthus to develop a cultivar of homogenous samples and superior accessions with health promoting effects. Therefore, the primary aim of our study was to determine the predominant phenolic acids and flavonoids of the different $M$. sacchariflorus accessions for use in breeding programs and the development of bioenergy crops with desirable traits.

\section{Materials and Methods}

\subsection{Chemicals}

Chemicals and solvents used in the present study were of analytical grade and were supplied by commercial providers. Methanol was obtained from J. T. Baker (Phillipsburg, NJ, USA). Compounds, such as 1,1-diphenyl-2-picrylhydrazyl (DPPH), 2,2'-azinobis 3-ethylbenzothiazoline-6-sulfonate (ABTS), quercetin, tetracycline, tert-butyl-4-hydroxy toluene (BHT), gallic acid, and Folin-Ciocalteu reagent were purchased from SigmaAldrich Chemical Co. (St. Louis, MO, USA). Standard phenolic compounds, including 5-sulfosalicylic acid, gallic acid, L-phenylalanine, homogentisic acid, protocatechuic acid, chlorogenic acid, catechin, daidzin, glycitin, orientin, rutin, $p$-hydroxybenzoic acid, caffeic acid, vitexin, vanillic acid, gentisic acid, polydatin, malonyldaidzin, naringin, genistin, $\beta$-resorcylic acid, acetyldaidzin, $p$-coumaric acid, ferulic acid, $m$-coumaric acid, veratric acid, myricetin, acetylgenistin, daidzein, glycitein, luteolin, quercetin, salicylic acid, apigenin, naringenin, genistein, kaempferol, hesperetin, formononetin, and biochanin A were obtained from Sigma Chemical Co. (St. Louis, MO, USA).

\subsection{Field Trials and Morphological Data Collection}

M. sacchariflorus accessions were originally collected from four different countries, but were grown under the same environmental conditions for more than 3 years. The plants 
were cultivated in the experimental fields of Kangwon National University, at Chuncheon, Kangwon-Do, South Korea $\left(37^{\circ} 51^{\prime} 12.21^{\prime \prime} \mathrm{N} ; 127^{\circ} 45^{\prime} 22.07^{\prime \prime}\right.$ E) at an average altitude of $97 \mathrm{~m}$. Experiments were conducted in a completely randomized block design with one plant in each plot. The experimental plots consisted of longitudinal rows separated by $1.5 \mathrm{~m}$ with plants placed every $1.5 \mathrm{~m}$ in rows. The temperature variation ranged from $-27.9^{\circ} \mathrm{C}$ (January) to $39.5^{\circ} \mathrm{C}$ (August), with $200 \mathrm{~mm}$ annual precipitation. Eight accessions were chosen from each ecotype to study their field performance, antioxidant activities, and phenolic compound composition. Detailed information regarding the area of ecogeographical distribution on the basis of latitude, longitude, and altitude is listed in Table 1. The experimental field was watered regularly during the first year using a drip-irrigation system. The experimental field was located in a temperate monsoon climate, with a wet and humid summer. The soil of the experimental field had a sandy loam texture. Black woven landscape fabric was used to control weeds by physically covering the area between the rows. Additional manual weed control was applied whenever necessary. For analysis of the morphological, biological, and phenolic compound, the plant samples were harvested at the beginning of October in 2015, 2016, and 2017. Five randomly selected plants from each ecogeographical origin were considered from each accession for the analysis of morphological traits. A total of 16 morphological traits were recorded in the growing season for each accession, including plant height, first heading date, 50\% heading date, culm length, culm outer diameter at the basal internode, culm node number, internode length, biomass yield fresh weight, biomass yield dry weight, moisture content, compressed plant circumference (CCirc)/basal circumference (BCirc), and total culm node number $(\mathrm{TCmN}) /$ area. For dry weight measurement of the samples, the harvested plants were oven dried at $80{ }^{\circ} \mathrm{C}$ for $24 \mathrm{~h}$ and then weighed. Plant height was represented by the vertical distance from the base of the plant to the tip of the stem. Days to flower represented the number of days between sowing and the date when approximately $50 \%$ of the plant flowered. Dimensions (width, height, and diameter) were measured using digital Vernier calipers (Aerospace, China Longsuit Enterprise, Hunan, China) and weight was measured by electronic balance (Denver Instrument Co., Arvada, CO, USA).

\subsection{Evaluation of DPPH Radical Scavenging Assay}

The antioxidant potentials of different accessions of $M$. sacchariflorus were estimated based on the radical scavenging capacities of antioxidant compounds using DPPH and ABTS radicals. The DPPH radical scavenging assay was carried out following the methods of Ghimire et al. [52] with some modifications. Initially, a fresh stock solution of DPPH was prepared by mixing $24 \mathrm{mg}$ of DPPH solution in $100 \mu \mathrm{L}$ of methanol. The stock solution was then stored at $-20^{\circ} \mathrm{C}$ until needed. The working solution was prepared by mixing $5 \mathrm{~mL}$ of stock solution with $22.5 \mathrm{~mL}$ methanol in $1 \mathrm{~mL}$ of plant extracts at various concentrations ( 0.05 to $5 \mathrm{mg} / \mathrm{mL}$ ); these were added to the same volume of DPPH solution and incubated for $30 \mathrm{~min}$ at room temperature $\left(25^{\circ} \mathrm{C}\right)$ in darkness. A blank was prepared consisting of methanol without DPPH. The absorbance value of the tested samples against a blank was measured at $517 \mathrm{~nm}$ using a spectrophotometer (Jasco V530 UV-VIS spectrophotometer, Japan). BHT (Sigma-Aldrich Co., St. Louis, MO, USA), a synthetic antioxidant, was used as a positive control. The exponential regression equation was used to calculate the $\mathrm{IC}_{50}$ (the concentrations required for $50 \%$ inhibition of the DPPH radicals present in the mixture). Measurements were performed in triplicate. 
Table 1. List of M. sacchariflorus accessions, origin, altitude, latitude, and longitude used in the study.

\begin{tabular}{ccccc}
\hline Accession & Origin & Latitude & Longitude & Elevation (m) \\
\hline MS-179 & China & 36.19179 & 120.38175 & -3 \\
MS-196 & China & 33.07787 & 118.1983 & 27 \\
MS-212 & China & 36.07295 & 120.36186 & 26 \\
MS-239 & China & 40.37234 & 123.59073 & 103 \\
MS-244 & China & 36.0758 & 120.33541 & 3 \\
MS-258 & China & 37.46181 & 118.40062 & 9 \\
MS-271 & China & 31.52864 & 118.46166 & 28 \\
MS-279 & China & 37.24615 & 121.45671 & -1 \\
MS-186 & Korea & 35.788876 & 127.083015 & 61 \\
MS-201 & Korea & 36.316388 & 128.554166 & 64 \\
MS-207 & Korea & 35.469166 & 129.215 & 57 \\
MS-241 & Korea & 36.232777 & 128.563611 & 83 \\
MS-247 & Korea & 37.196791 & 127.874303 & 236 \\
MS-274 & Korea & 36.451666 & 127.451944 & 37 \\
MS-278 & Korea & 37.778228 & 127.371022 & 142 \\
MS-447 & Korea & 35.695697 & 128.3224 & 16 \\
MS-248 & Japan & 35.63627 & 136.94965 & 123 \\
MS-249 & Japan & 34.93411 & 133.33 & 362 \\
MS-190 & Japan & 38.72429 & 139.85879 & 15.6 \\
MS-231 & Japan & 42.57628 & 140.79830 & 87 \\
MS-422 & Japan & 35.37239 & 136.77384 & 14.5 \\
MS-425 & Japan & 38.37632 & 140.31934 & 90.4 \\
MS-448 & Japan & 43.411547 & 144.52969 & 63.95 \\
MS-530 & Japan & 42.66314 & 141.759849 & 4 \\
MS-232 & Russia & 48.6669 & 132.982 & 69 \\
MS-233 & Russia & 48.6241 & 135.13425 & 28 \\
MS-253 & Russia & 43.75277 & 132.0803 & 59 \\
MS-240 & Russia & 49.0646 & 136.5176 & 21 \\
MS-394 & Russia & 48.36315 & 135.0705 & 67 \\
MS-403 & Russia & 48.5213 & 134.95441 & 35 \\
MS-421 & Russia & 46.865 & 134.269 & 113 \\
MS-430 & Russia & 44.69109 & 131.95929 & \\
\hline & & & & \\
\hline
\end{tabular}

\subsection{Evaluation of ABTS Radical Scavenging Assay}

ABTS radical scavenging potentials of different accessions of $M$. sacchariflorus were measured following the method described by Ghimire et al. [52] with some modifications. The ABTS (Sigma-Aldrich Co., St. Louis, MO, USA) stock solution was prepared by reacting $7.4 \mathrm{mM}$ ABTS aqueous solution with $2.6 \mathrm{mM}$ potassium persulfate (Daejung, Siheung, Korea) in equal volumes (1:1). After gentle agitation, the solution was allowed to react for $12-14 \mathrm{~h}$ at room temperature $\left(25^{\circ} \mathrm{C}\right)$ in darkness. Subsequently, $1 \mathrm{~mL}$ of plant extracts at various concentrations (or $1 \mathrm{~mL}$ of standard trolox) were mixed with an equal volume of ABTS solution. The mixture was then incubated at room temperature $\left(25^{\circ} \mathrm{C}\right)$ for $2 \mathrm{~h}$ in darkness. The control was prepared by mixing $1 \mathrm{~mL}$ of ABTS solution and $500 \mu \mathrm{L}$ of distilled water. The absorbance of the control and the plant samples was recorded at $734 \mathrm{~nm}$ using a spectrophotometer (Jasco V530 UV-VIS spectrophotometer, Japan). The exponential regression equation was used to calculate the $\mathrm{IC}_{50}$ (concentration required for $50 \%$ inhibition of ABTS radical present in the mixture). Measurements were performed in triplicate.

\subsection{Determination of Total Phenolic Content}

The total phenolic content was determined by Folin-Ciocalteu colorimetric assay as described by Chung et al. [53], with slight modifications. Initially, $100 \mu \mathrm{L}$ of plant extract $(1 \mathrm{mg} / \mathrm{mL}$ ) was added to $50 \mu \mathrm{L}$ of Folin-Ciocalteu reagent in a 96-well plate (SPL Life Sciences Co., Gyeonggi-do, Korea). The mixture was then incubated for $5 \mathrm{~min}$ at room temperature $\left(25^{\circ} \mathrm{C}\right)$ in darkness. Next, $100 \mu \mathrm{L}$ of $20 \%(w / v)$ sodium carbonate was added to 
the mixture and shaken well. The mixture was incubated for $12 \mathrm{~min}$ at room temperature. The absorbance of the sample was measure at $725 \mathrm{~nm}$ against the blank using a microplate reader (Multiskan GO, Thermo Fisher Scientific, Shanghai Instruments, China) connected to a Shimadzu UV-VIS spectrophotometer (UV-1800, Shimadzu, Kyoto, Japan). A calibration curve was prepared using different concentration of gallic acid $(0,65.5,125$, and $250 \mathrm{mg}$ $\mathrm{L}^{-1}$ ). Total phenolic values were expressed in terms of the gallic acid equivalent (GAE) of dry plant matter per gram powder ( $\mu \mathrm{g} \mathrm{Qg}^{-1}$ dry weight), using the following equation,

$$
y=0.3208 x-0.3208
$$

where $x$ is the quantity of gallic acid equivalent $\left(\mu \mathrm{g} \mathrm{mL}^{-1}\right)$ and $y$ is the absorbance at $765 \mathrm{~nm}$.

\subsection{Determination of Total Flavonoid Content}

The quantity of total flavonoid present in the accessions of $M$. sacchariflorus was determined following the methods of Chung et al. [53]. Initially, $500 \mu \mathrm{L}$ of $1 \mathrm{mg} / \mathrm{mL}$ extracts of various accessions of $M$. sacchariflorus was added to $100 \mu \mathrm{L}$ of $10 \%$ aluminum nitrate and $100 \mu \mathrm{L}$ of potassium acetate. Next, $1 \mathrm{~mL}$ of $\mathrm{NaOH}(1 \mathrm{M})$ was added to the mixture at room temperature $\left(25^{\circ} \mathrm{C}\right)$ and left for $30 \mathrm{~min}$. A blank was prepared by following same method and substituting the plant sample with an equal amount of methanol. The absorbance of each accession extract was measured against a blank at $510 \mathrm{~nm}$ using a Shimadzu UV-VIS spectrophotometer (UV-1800, Shimadzu, Kyoto, Japan). The calibration curve was prepared using $0.5,10$, and $100 \mathrm{~mL}$ solutions of quercetin. The total flavonoid valued was expressed in terms of quercetin equivalent $(\mathrm{Qu})$ per gram of the dry plant matter using the following equation,

$$
y=1.0707 x-1.0183
$$

where $x$ is the quantity of quercetin equivalent $\left(\mu \mathrm{g} \mathrm{mL}^{-1}\right)$ and $y$ is the absorbance at $510 \mathrm{~nm}$.

\subsection{Quantification of Phenolic Compounds by Liquid Chromatography-Mass Spectrometry/Mass Spectrometry (LC-MS/MS)}

The concentrations and compositions of phenolic compounds in the accessions of M. sacchariflorus were quantified using liquid chromatography-mass spectrometry/mass spectrometry system as described previously by Chung et al. [53], with slight modifications. The LC-MS/MS system consisted of a pump (Agilent 1200) and an autosampler (Agilent 1100 series, Agilent Technologies, Palo Alto, CA, USA) coupled to an API 2000 series mass spectrometer (Applied Biosystems, Vaughan, ON, Canada). LC-MS/MS analysis of the phenolic compounds was performed using a Thermo Scientific Syncronis C18 column $(4.6 \times 250 \mathrm{~mm}, 5 \mu \mathrm{m})$. The mass spectrometer was operated in negative ion mode with the following parameters: nebulizer gas pressure, 40 psi (air); drying gas pressure, 70 psi (nitrogen); drying gas temperature, $350^{\circ} \mathrm{C}$; capillary voltage, $4.5 \mathrm{kV}$; collision gas pressure, 2 psi; and curtain gas pressure, 20 psi. The mobile phase consisted of $0.1 \%$ formic acid in water (solution A) and acetonitrile in water (solution B). The mobile phase gradient parameters were maintained in the following order: $0-10 \mathrm{~min}, 10-40 \% \mathrm{~B} ; 10-20 \mathrm{~min}, 40-50 \%$ B; 20-25 min, 50-100\% B; 25-26 min, 100-10\% B; 26-30 min, 10\% B. The temperature of the column was $25^{\circ} \mathrm{C}$ and the volume of injection was $10 \mu \mathrm{L}$. The flow rate of the mobile phase was fixed at $0.7 \mathrm{~mL} \mathrm{~min}^{-1}$. Mass-spectrometry data were recorded using the electrospray ion source (ESI) in negative mode under the multiple reaction monitoring (MRM) mode. The molecular ions $(\mathrm{m} / \mathrm{z}$ ) and major fragments $(\mathrm{m} / \mathrm{z})$ were monitored on the first quadrupole and third quadrupole, respectively. Mass spectrometric parameters such as declustering potential (DP), entrance potential (EP), collision cell exit potential (CXP), collision energy (CE), and cell entrance potential (CEP) were optimized for each MRM transition monitored. All chemical analyses for each sample (accession) were carried out in triplicate. 


\subsection{Statistical Analysis}

The data shown represent the mean \pm standard deviation. The data were statistically evaluated using analysis of variance (ANOVA) and significant differences between the means were assessed using Duncan's multiple range test. Interrelationships among phenotypic traits, phenolic compounds, and antioxidant properties were determined by Pearson's correlation coefficient using SPSS version 20 (SPSS, IBM, New York, NY, USA, 2011. Principal component analysis (PCA) of morphological traits and phenolic compounds was performed using SPSS version 20.

\section{Results}

\subsection{Morphological Trait Variation in M. sacchariflorus Accessions}

Thirty-two accessions of M. sacchariflorus collected from different provinces of South Korea, China, Japan, and Russia were evaluated for twelve distinctive morphological traits including plant height heading date, flowering date, culm length, fresh weight and dry weight, culm diameter and number, and culm node number (Tables 2 and 3). According to ANOVA analysis, the results displayed significant variation in the morphological traits among individuals. The accessions displayed a wide range of variation in plant height, ranging from $18.00 \pm 1.00 \mathrm{~cm}$ to $163.20 \pm 4.00 \mathrm{~cm}$. The majority of the Japanese accessions displayed lower plant height than the other accessions.

Table 2. Morphological characteristics of the selected M. sacchariflorus accessions.

\begin{tabular}{|c|c|c|c|c|c|c|c|}
\hline${ }^{2}$ Acc. No. & Plant Height (cm) & $\begin{array}{c}{ }^{1} \text { HD } \\
\text { (days) }\end{array}$ & $\begin{array}{c}\text { HD50\% } \\
\text { (days) }\end{array}$ & $\begin{array}{c}\text { FD } \\
\text { (days) }\end{array}$ & $\begin{array}{c}\text { FD } 50 \% \\
\text { (days) }\end{array}$ & TC & CL (cm) \\
\hline MS-179 & $52.50 \pm 2.00^{j}$ & 172 & 187 & 194 & 201 & $248.50 \pm 5.00^{s}$ & $182.10 \pm 4.00^{\mathrm{m}}$ \\
\hline MS-196 & $115.00 \pm 1.50^{x}$ & 142 & 158 & 184 & 201 & $386.50 \pm 4.00^{x}$ & $214.50 \pm 2.00^{u}$ \\
\hline MS-212 & $61.00 \pm 2.00^{\mathrm{m}}$ & 142 & 158 & 184 & 201 & $222.10 \pm 6.00 \mathrm{p}$ & $271.30 \pm 6.00$ ee \\
\hline MS-239 & $147.10 \pm 3.00^{z}$ & 155 & 169 & 187 & 194 & $825.50 \pm 8.00^{z}$ & $172.50 \pm 2.00^{j}$ \\
\hline MS-244 & $56.50 \pm 1.50^{\mathrm{k}}$ & 172 & 187 & 194 & 211 & $71.10 \pm 2.00^{c}$ & $214.20 \pm 3.00^{\mathrm{u}}$ \\
\hline MS-258 & $163.20 \pm 4.00^{\mathrm{bb}}$ & 172 & 187 & 194 & 211 & $176.60 \pm 5.00^{\mathrm{k}}$ & $265.20 \pm 5.00^{\mathrm{dd}}$ \\
\hline MS-271 & $61.10 \pm 1.20 \mathrm{mn}$ & 156 & 170 & 187 & 194 & $96.10 \pm 2.00^{\mathrm{f}}$ & $242.10 \pm 9.00^{z}$ \\
\hline MS-279 & $27.20 \pm 1.10^{c}$ & 172 & 187 & 194 & 211 & $219.50 \pm 5.50^{\circ}$ & $196.10 \pm 5.00^{\circ}$ \\
\hline MS-186 & $49.50 \pm 1.70^{h}$ & 155 & 169 & 184 & 201 & $150.10 \pm 3.00^{j}$ & $202.00 \pm 2.00^{p}$ \\
\hline MS-201 & $151.40 \pm 3.00^{\text {aa }}$ & 155 & 169 & 184 & 201 & $299.50 \pm 6.00 \mathrm{vw}$ & $207.50 \pm 7.00^{s}$ \\
\hline MS-207 & $49.11 \pm 2.00^{h}$ & 155 & 169 & 184 & 201 & $500.90 \pm 7.00^{y}$ & $124.50 \pm 6.00^{f}$ \\
\hline MS-241 & $43.20 \pm 1.50 \mathrm{~g}$ & 142 & 158 & 184 & 201 & $228.50 \pm 4.00^{r}$ & $175.10 \pm 2.00^{k}$ \\
\hline MS-247 & $50.10 \pm 1.50^{\mathrm{i}}$ & 142 & 158 & 184 & 201 & $203.10 \pm 2.00^{1}$ & $247.20 \pm 6.00^{b b}$ \\
\hline MS-274 & $103.00 \pm 4.00^{\mathrm{v}}$ & 135 & 142 & 158 & 170 & $94.60 \pm 2.00$ ef & $223.20 \pm 7.00^{x}$ \\
\hline MS-278 & $92.00 \pm 2.00^{t}$ & 142 & 158 & 184 & 201 & $97.70 \pm 3.00 \mathrm{fg}$ & $232.50 \pm 8.00^{y}$ \\
\hline MS-447 & $57.50 \pm 1.00^{1}$ & 135 & 142 & 158 & 168 & $297.50 \pm 7.00^{v}$ & $260.20 \pm 5.00^{c c}$ \\
\hline MS-248 & $40.20 \pm 1.50^{\mathrm{e}}$ & 142 & 158 & 184 & 201 & $101.20 \pm 4.00^{g}$ & $217.30 \pm 6.00^{v}$ \\
\hline MS-249 & $39.20 \pm 1.00^{\mathrm{d}}$ & 113 & 132 & 145 & 152 & $93.10 \pm 2.00^{\mathrm{e}}$ & $186.20 \pm 5.00^{n}$ \\
\hline MS-190 & $20.20 \pm 1.30^{b}$ & 142 & 158 & 184 & 201 & $74.40 \pm 1.00^{\mathrm{d}}$ & $243.00 \pm 2.00$ aа \\
\hline MS-231 & $98.20 \pm 2.80^{\mathrm{u}}$ & 185 & 201 & 0 & 0 & $222.20 \pm 8.00 \mathrm{p}$ & $203.50 \pm 4.00 \mathrm{q}$ \\
\hline MS-422 & $41.11 \pm 2.00^{\mathrm{f}}$ & 156 & 170 & 187 & 194 & $46.30 \pm 1.00^{\mathrm{a}}$ & $206.50 \pm 7.00^{r}$ \\
\hline MS-425 & $62.20 \pm 2.00^{n}$ & 156 & 170 & 187 & 194 & $68.20 \pm 1.00^{b}$ & $222.80 \pm 6.70^{w}$ \\
\hline MS-448 & $18.10 \pm 1.00^{\mathrm{a}}$ & 113 & 132 & 145 & 152 & $213.20 \pm 5.00^{\mathrm{m}}$ & $110.80 \pm 6.40^{d}$ \\
\hline MS-530 & $67.10 \pm 2.90^{\text {no }}$ & 156 & 170 & 187 & 194 & $110.20 \pm 3.00^{h}$ & $178.10 \pm 6.20^{1}$ \\
\hline MS-232 & $74.50 \pm 2.00^{p}$ & 106 & 111 & 132 & 142 & $324.30 \pm 8.00^{w}$ & $147.20 \pm 6.00^{h}$ \\
\hline MS-233 & $71.00 \pm 1.90^{\circ}$ & 88 & 106 & 121 & 132 & $69.50 \pm 4.00^{b c}$ & $75.10 \pm 2.00^{\mathrm{a}}$ \\
\hline MS-253 & $89.10 \pm 2.00^{\mathrm{s}}$ & 88 & 106 & 121 & 132 & $123.20 \pm 3.00^{\mathrm{i}}$ & $123.20 \pm 6.00^{\mathrm{e}}$ \\
\hline MS-240 & $80.50 \pm 2.00^{\mathrm{r}}$ & 95 & 106 & 113 & 132 & $280.10 \pm 6.00^{u}$ & $212.20 \pm 5.00^{t}$ \\
\hline MS-394 & $115.20 \pm 2.00^{x}$ & 76 & 81 & 88 & 106 & $272.30 \pm 8.00^{t}$ & $133.30 \pm 2.00 \mathrm{~g}$ \\
\hline MS-403 & $75.20 \pm 3.00^{q}$ & 76 & 81 & 88 & 106 & $204.20 \pm 3.00 \mathrm{~lm}$ & $93.20 \pm 6.00^{b c}$ \\
\hline MS-421 & $104.09 \pm 3.00^{w}$ & 88 & 106 & 121 & 132 & $224.50 \pm 4.00^{\mathrm{q}}$ & $94.20 \pm 6.00^{c}$ \\
\hline MS-430 & $141.20 \pm 2.00^{y}$ & 88 & 106 & 121 & 132 & $217.10 \pm 5.00^{\mathrm{n}}$ & $164.30 \pm 6.00^{\mathrm{i}}$ \\
\hline
\end{tabular}

${ }^{1}$ HD: first heading date, HD 50: 50\% heading date, FD: first flowering date, FD 50\%: 50\% flowering date, culm length; TC: total culm; CL: culm length. Mean values within a column with the same lowercase letters were not significantly different $(p<0.05)$ according to Duncan's multiple comparison test. ${ }^{2}$ Acc. no.: accession number. 
Table 3. Morphological characteristics of the selected M. sacchariflorus accessions.

\begin{tabular}{|c|c|c|c|c|c|c|c|c|}
\hline Acc. No. & ${ }^{1} \mathrm{COD}(\mathrm{mm})$ & $\mathrm{CNN}$ & AIL (cm) & Fresh Weight (g) & Dry Weight (g) & $\begin{array}{c}\text { Moisture } \\
\text { Content (\%) }\end{array}$ & CCirc/BCirc & TCmN/Area \\
\hline MS-179 & $4.00^{c}$ & 16 & $11.38 \pm 1.10^{\mathrm{d}}$ & $2002.00 \pm 15.01^{\mathrm{k}}$ & $1210.00 \pm 10.00 \mathrm{q}$ & 39.50 & 0.30 & 0.0128 \\
\hline MS-196 & $5.00^{\mathrm{d}}$ & 14 & $15.29 \pm 1.90^{h}$ & $2806.00 \pm 17.02^{\circ}$ & $1750.00 \pm 10.00^{\mathrm{w}}$ & 37.50 & 0.20 & 0.0120 \\
\hline MS-212 & 6.10 ef & 17 & $15.94 \pm 1.50^{h}$ & $3100.00 \pm 19.00 \mathrm{p}$ & $1822.80 \pm 12.00^{x}$ & 41.20 & 0.20 & 0.0283 \\
\hline MS-239 & $4.12^{\mathrm{c}}$ & 11 & $15.64 \pm 1.30^{h}$ & $2104.00 \pm 14.03^{1}$ & $1386.00 \pm 90.00^{\mathrm{s}}$ & 34.00 & 0.40 & 0.0268 \\
\hline MS-244 & $8.11^{\mathrm{h}}$ & 10 & $16.33 \pm 2.00^{i}$ & $203.00 \pm 10.00^{\mathrm{e}}$ & $141.00 \pm 4.00^{\mathrm{h}}$ & 29.50 & 0.10 & 0.0133 \\
\hline MS-258 & $6.13^{\text {ef }}$ & 18 & $15.38 \pm 1.50^{h}$ & $2201.00 \pm 18.00 \mathrm{~m}$ & $1507.00 \pm 10.00^{\mathrm{v}}$ & 31.50 & 0.10 & 0.0158 \\
\hline MS-271 & $10.00^{\mathrm{i}}$ & 21 & $14.72 \pm 1.30^{g}$ & $5405.00 \pm 20.01^{t}$ & $3429.00 \pm 18.00^{b b}$ & 36.50 & 0.10 & 0.0110 \\
\hline MS-279 & $4.11^{\mathrm{c}}$ & 17 & $15.47 \pm 1.70^{\mathrm{h}}$ & $501.00 \pm 11.00 \mathrm{~g}$ & $315.00 \pm 7.00^{j}$ & 37.00 & 0.10 & 0.0142 \\
\hline MS-186 & 6.00 ef & 15 & $13.47 \pm 1.11^{\mathrm{f}}$ & $3802.00 \pm 20.01 \mathrm{q}$ & $2584.00 \pm 20.40^{y}$ & 32.00 & 0.20 & 0.0096 \\
\hline MS-201 & $10.00^{\mathrm{i}}$ & 16 & $12.94 \pm 1.30^{\mathrm{e}}$ & $4801.00 \pm 18.00^{r}$ & $3225.60 \pm 20.20^{\text {aa }}$ & 32.80 & 0.50 & 0.0178 \\
\hline MS-207 & $5.00^{\mathrm{d}}$ & 12 & $10.33 \pm 1.00^{c}$ & $2103.00 \pm 20.00^{1}$ & $1375.50 \pm 10.00^{r}$ & 34.50 & 0.30 & 0.0489 \\
\hline MS-241 & $5.11^{\mathrm{d}}$ & 12 & $14.58 \pm 1.20^{g}$ & $2402.00 \pm 20.01^{n}$ & $1596.00 \pm 9.00^{\mathrm{v}}$ & 33.50 & 0.30 & 0.0236 \\
\hline MS-247 & 6.00 ef & 16 & $21.40 \pm 1.20^{\mathrm{k}}$ & $1400.00 \pm 14.01^{j}$ & $963.20 \pm 10.00 \mathrm{p}$ & 31.20 & 0.10 & 0.0189 \\
\hline MS-274 & $5.22^{\mathrm{d}}$ & 15 & $11.52 \pm 1.10^{\mathrm{d}}$ & $2202.00 \pm 20.01^{\mathrm{m}}$ & $1421.20 \pm 10.00^{\mathrm{u}}$ & 35.40 & 0.20 & 0.0248 \\
\hline MS-278 & $4.00^{\mathrm{c}}$ & 15 & $14.87 \pm 2.00^{g}$ & $2205.00 \pm 23.00 \mathrm{~m}$ & $1397.00 \pm 20.00^{t}$ & 36.50 & 0.20 & 0.0148 \\
\hline MS-447 & $7.00 \mathrm{~g}$ & 14 & $18.57 \pm 1.90^{\mathrm{j}}$ & $1402.00 \pm 12.00^{j}$ & $952.00 \pm 15.00^{\circ}$ & 32.00 & 0.10 & 0.0155 \\
\hline MS-248 & $5.11^{\mathrm{d}}$ & 18 & $15.44 \pm 1.10^{h}$ & $500.00 \pm 9.00 \mathrm{~g}$ & $320.00 \pm 10.00^{k}$ & 36.00 & 0.20 & 0.0148 \\
\hline MS-249 & 6.12 ef & 13 & $12.06 \pm 1.19^{\mathrm{e}}$ & $5000.00 \pm 23.00^{\mathrm{s}}$ & $2825.00 \pm 7.00^{z}$ & 43.50 & 0.20 & 0.0093 \\
\hline MS-190 & $10.00^{\mathrm{i}}$ & 18 & $13.50 \pm 1.20^{f}$ & $600.03 \pm 14.00^{h}$ & $372.00 \pm 10.00^{1}$ & 38.00 & 0.10 & 0.0050 \\
\hline MS-231 & $7.00^{g}$ & 14 & $14.50 \pm 1.50^{g}$ & $503.00 \pm 10.00 \mathrm{~g}$ & $321.00 \pm 7.00^{k}$ & 35.80 & 0.10 & 0.0048 \\
\hline MS-422 & 6.12 ef & 24 & $10.44 \pm 1.00^{c}$ & $904.00 \pm 13.00^{\mathrm{i}}$ & $589.50 \pm 10.00^{\mathrm{m}}$ & 34.50 & 0.10 & 0.0128 \\
\hline MS-425 & $5.11^{\mathrm{d}}$ & 16 & $13.88 \pm 1.20^{f}$ & $1403.00 \pm 12.00^{j}$ & $910.00 \pm 20.00^{n}$ & 35.00 & 0.10 & 0.0150 \\
\hline MS-448 & $4.33^{c}$ & 14 & $7.86 \pm 1.00^{a}$ & $150.00 \pm 7.00^{c}$ & $100.50 \pm 4.02^{d}$ & 33.00 & 0.10 & 0.0197 \\
\hline MS-530 & $5.23^{\mathrm{d}}$ & 11 & $15.18 \pm 1.50^{h}$ & $504.00 \pm 10.00 \mathrm{~g}$ & $315.00 \pm 10.00^{j}$ & 37.00 & 0.10 & 0.0136 \\
\hline MS-232 & $2.00^{b}$ & 8 & $18.38 \pm 2.00^{j}$ & $181.03 \pm 12.00^{\mathrm{d}}$ & $113.40 \pm 4.00^{f}$ & 37.00 & 0.20 & 0.0065 \\
\hline MS-233 & $2.11^{b}$ & 8 & $9.38 \pm 1.00^{\mathrm{b}}$ & $153.04 \pm 11.00^{c}$ & $99.75 \pm 3.00^{c}$ & 33.50 & 0.40 & 0.0293 \\
\hline MS-253 & $1.01^{\mathrm{a}}$ & 8 & $14.31 \pm 1.13^{g}$ & $504.08 \pm 19.00^{g}$ & $327.50 \pm 10.00^{j}$ & 34.50 & 0.10 & 0.0069 \\
\hline MS-240 & $4.11^{c}$ & 14 & $15.14 \pm 1.10^{h}$ & $123.00 \pm 11.00^{\mathrm{a}}$ & $82.80 \pm 3.00^{a}$ & 31.00 & 0.10 & 0.0084 \\
\hline MS-394 & $4.12^{\mathrm{c}}$ & 12 & $11.53 \pm 1.00^{\mathrm{d}}$ & $250.03 \pm 14.00^{f}$ & $161.25 \pm 4.00^{i}$ & 35.50 & 0.20 & 0.0911 \\
\hline MS-403 & $4.10^{c}$ & 9 & $11.08 \pm 0.90^{\mathrm{d}}$ & $150.02 \pm 11.00^{c}$ & $103.50 \pm 5.02^{\mathrm{e}}$ & 31.00 & 0.10 & 0.0239 \\
\hline MS-421 & 6.17 ef & 9 & $10.33 \pm 0.80^{c}$ & $200.00 \pm 13.00^{\mathrm{e}}$ & $126.00 \pm 7.03 \mathrm{~g}$ & 37.00 & 0.80 & 0.0696 \\
\hline MS-430 & $4.15^{c}$ & 11 & $14.91 \pm 1.10^{g}$ & $146.00 \pm 11.00^{b}$ & $93.44 \pm 6.04^{b}$ & 36.00 & 0.20 & 0.0101 \\
\hline
\end{tabular}

${ }^{1}$ COD: culm out diameter, CNN: culm node number, AIL: average internode length, CCirc: compressed plant circumference, BCirc: basal circumference, TCmN: total culm node number. Mean values within a column with the same lowercase letters were not significantly different $(p<0.05)$ according to Duncan's multiple comparison test.

The degree of correlation between some important morphological traits in the MS accessions may be useful for phenotypic characterization, taxonomy, and the improvement of accessions in breeding programs. Pearson's correlation study was conducted to illustrate the relationship between morphological traits within M. sacchariflorus accessions (Table 4). Plant height was significantly correlated with biomass yield (fresh weight; $r=0.439$, $p<0.05)$ and was moderately positively correlated with culm length $(r=0.356, p<0.05)$ that may directly affect the physiological and biological properties of the plant. Culm length (an important trait in plant breeding) had pronounced variations, ranging from $75.10 \pm 2.00$ to $271.30 \pm 6.00 \mathrm{~cm}$. On average, the majority of the Russian accessions exhibited shorter culm lengths. Similarly, the majority of the Russian accessions displayed smaller culm outer diameters and lower culm node numbers. Culm length was moderately correlated with the biomass yield fresh weight $(r=0.419, p<0.05)$ and biomass yield dry weight $(r=0.425, p<0.05)$; however, it exhibited weak and negative correlations with CCirc $(r=-0.374, p<0.05)$ and TCmN $(r=-0.440, p<0.05)$. Culm outer diameter at the basal internode varied widely among the accessions, ranging from 1.01 to $10.00 \mathrm{~mm}$. Significant and moderately positive correlations were found between culm outer diameter and biomass yield fresh weight $(r=0.484, p<0.01)$ and biomass yield dry weight $(r=0.499$, $p<0.01$ ). 
Table 4. Pearson's correlation coefficients between the main morphological characteristics in M. sacchariflorus accessions.

\begin{tabular}{|c|c|c|c|c|c|c|c|c|c|c|c|c|c|c|c|}
\hline & PH & HD & HD 50\% & FD & FD 50\% & $\mathrm{CN}$ & CL & COD & CNN & AIL & $\begin{array}{c}\text { Fresh } \\
\text { Weight }\end{array}$ & $\begin{array}{c}\text { Dry } \\
\text { Weight }\end{array}$ & $\begin{array}{c}\text { Moisture } \\
\text { Content }\end{array}$ & ${ }^{1}$ CCirc/BCirc & TCmN/Area \\
\hline $\mathrm{PH}$ & 1 & -0.122 & -0.135 & -0.218 & -0.206 & $0.391 *$ & -0.013 & -0.058 & -0.225 & 0.082 & 0.095 & 0.122 & -0.158 & 0.335 & 0.209 \\
\hline HD & & 1 & 0.993 ** & $0.505^{* *}$ & $0.469^{* *}$ & 0.036 & $0.628^{* *}$ & $0.492 * *$ & $0.568^{* *}$ & 0.277 & 0.362 * & 0.383 * & 0.019 & -0.161 & $-0.388^{*}$ \\
\hline HD 50\% & & & 1 & $0.513^{* *}$ & $0.475^{* *}$ & 0.013 & $0.607 * *$ & $0.487^{* *}$ & $0.564^{* *}$ & 0.251 & $0.368^{*}$ & $0.386^{*}$ & 0.050 & -0.127 & $-0.404^{*}$ \\
\hline $\mathrm{FD}$ & & & & 1 & 0.994 ** & -0.002 & $0.457^{* *}$ & 0.255 & 0.445 * & 0.210 & 0.413 * & 0.428 * & 0.042 & 0.021 & -0.193 \\
\hline FD 50\% & & & & & 1 & 0.000 & $0.455^{* *}$ & 0.250 & $0.428 *$ & 0.221 & 0.398 * & $0.415 *$ & 0.007 & 0.020 & -0.162 \\
\hline $\mathrm{CN}$ & & & & & & 1 & -0.163 & -0.164 & -0.267 & 0.123 & 0.064 & 0.080 & -0.081 & 0.328 & 0.252 \\
\hline CL & & & & & & & 1 & $0.566^{* *}$ & $0.699 * *$ & $0.600 * *$ & $0.419 *$ & $0.425 *$ & 0.068 & $-0.374 *$ & $-0.440 *$ \\
\hline COD & & & & & & & & 1 & 0.540 ** & 0.117 & $0.484 * *$ & $0.499 * *$ & -0.012 & 0.010 & -0.122 \\
\hline CNN & & & & & & & & & 1 & 0.047 & 0.393 * & 0.400 * & 0.135 & -0.291 & -0.265 \\
\hline AIL & & & & & & & & & & 1 & 0.031 & 0.043 & -0.114 & -0.311 & $-0.376^{*}$ \\
\hline Dry weight & & & & & & & & & & & & 1 & 0.219 & 0.152 & -0.151 \\
\hline $\begin{array}{c}\text { Moisture } \\
\text { content }\end{array}$ & & & & & & & & & & & & & 1 & 0.166 & 0.003 \\
\hline $\begin{array}{l}\text { CCirc/BCirc } \\
\text { TCmN/Area }\end{array}$ & & & & & & & & & & & & & & 1 & $\begin{array}{c}0.509 \text { ** } \\
1\end{array}$ \\
\hline
\end{tabular}

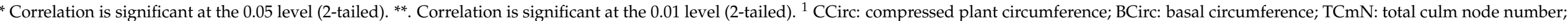

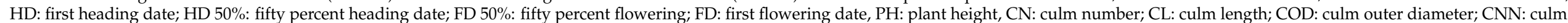
node number; AIL: average internode length. 
Remarkable variation was observed in the First Heading Date metric, ranging from 76 to 185 days in MS-394 and MS-231, respectively. Comparatively, the Russian accessions showed the earliest first heading date (76 to 106 days), 50\% heading date (81 to 111 days), first flower date (88 to 132 days), and 50\% flowering date (106 to 142 days), as compared to other groups of accessions. The greatest within-group variation for these parameters was observed in the Japanese accessions. Moreover, significantly higher positive correlations were found between first heading date and fifty heading data $(r=0.993, p<0.01)$ and the date of first flowering $(r=0.505, p<0.01)$, indicating that the spring regrowth date and the first heading date of the accessions were critical factors that directly influenced the initiation of flowering in M. sacchariflorus. The majority of the Chinese accessions showed longer periods of first heading date and first flowering date. The Russian accessions MS394 and MS-403 showed the shortest times for first heading date and first flowering date, respectively. Both first heading date and first flowering date showed a moderate association with the biomass yield fresh weight $(r=0.362, p<0.05$ and $r=0.413, p<0.05$, respectively).

The majority of the accessions showed early spring regrowth (first week of April). Some of the Japanese accessions (MS-247, MS-248, MS-249, MS-190, and MS-253) showed late spring regrowth, but the date of regrowth did not yield any effect on the first heading date, $50 \%$ heading date, and biomass of the plant. Substantial variation in biomass yield fresh weight was observed, ranging from $123.00 \pm 11.00 \mathrm{~g}$ to $5405.00 \pm 20.01 \mathrm{~g}$ (Table 3). The majority of the Chinese and Korean accessions displayed higher biomass yield (fresh weight and dry weight). In contrast, the Russian accessions had lower biomass yields (fresh weight and dry weight). Significant variation in morphological traits in the M. sacchariflorus accessions indicates that the collected accessions contain valuable traits and genes that could supply the material for breeding programs in the future.

\subsubsection{Principal Component Analysis (PCA)}

PCA is a widely used tool for obtaining overviews of complex datasets that has also been used for reducing dimensions and revealing relationships among data items. In this study, PCA was applied to assess the variation in the 16 morphological traits in 32 accessions of $M$. sacchariflorus. The first and second principal components yielded 35.89\% and $15.35 \%$ of the total variance, respectively (Figure 1). As shown in the PCA diagram, we identified groups of accessions using the morphological traits. Along axis 1 of the PCA analysis, 13 accessions (the majority of which comprised Chinese and Russian accessions) were grouped on the positive side (MS-179, MS-186, MS-196, MS-201, MS-207, MS-212, MS-231, MS-239, MS-241, MS-258, MS-271, MS-274, and MS-278) and strongly contributed to morphological traits, such as fresh weight, dry weight, moisture content, culm outer diameter, first flowering date, and 50\% flowering date. Four other accessions (MS-207, MS-233, MS-394, and MS-421), the majority of which comprised Korean accessions, were negatively correlated with the morphological characters of plant height, culm number, TcmN/Area, and CCirc/BCirc. Along axis 2 of the PCA analysis, nine other accessions (MS-190, MS-244, MS-247, MS-248, MS-279, MS-422, MS-425, MS-447, and MS-530) formed an additional group on the positive side of the PC2 axis and were primarily characterized by the morphological traits of culm length, culm node number, first heading date, 50\% heading date, and internode length. The remaining accessions (MS-232, MS-240, MS-249, MS-253, MS-403, MS-430, and MS-448) formed a separate group in the negative region of PC2 axis comprised mainly of Japanese accessions, indicating that accessions in this group have closely related genotypes. 


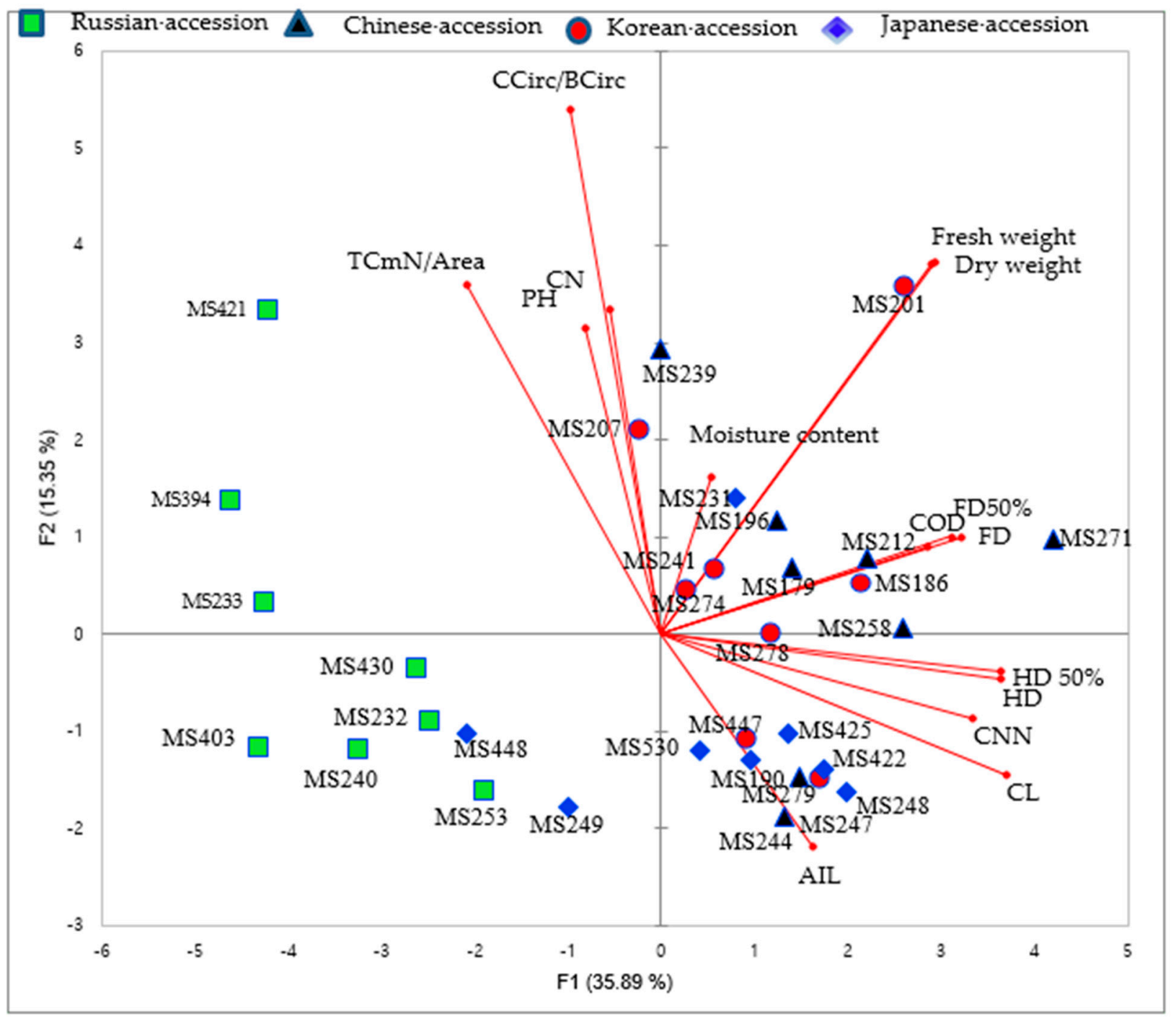

Figure 1. Two-dimensional plot of PC1 and PC2 principal coordinates analysis in the selected accessions of M. sacchariflorus based on morphological traits. COD: culm out diameter, CNN: culm node number, AIL: average internode length, CCirc: compressed plant circumference, BCirc: basal circumference, TCmN: total culm node number. ${ }^{1} \mathrm{HD}$ : first heading date, HD 50\%: 50\% heading date, FD: first flowering date, FD 50\%: 50\% flowering date, CN, culm number; TC: total culm; CL: culm length, $\mathrm{PH}$ : plant height, $\mathrm{TCmN}$, total culm node number.

3.1.2. Unweighted Pair Group Method with Arithmetic Mean (UPGMA) Cluster Analysis Using Morphological Traits

Cluster analysis of 17 morphological traits of 32 accessions of $M$. sacchariflorus yielded two major groups (Figure 2). The first cluster consisted of four accessions and was further divided into two subgroups. Subgroup I-A consisted of a lone Korean accession (MS-186); Subgroup I-B comprised three accessions (MS-448, MS-278, and MS-271), which were characterized by identical moisture content, culm outer diameter, first flowering date, 50\% flowering date, biomass yield fresh weight, and biomass yield dry weight. The second major group (II) consisted of 28 accessions and was further divided into two subgroups. Subgroup II-A consisted of nine accessions of primarily Japanese and Korean origin. The remainder of the accessions formed the Group II-B, which primarily comprised Russian accessions sharing the characteristics of higher TCmN/Area 2017 (CmN/A), plant height, culm number, and CCirc/BCirc. However, the number of accessions used in this study was relatively small for making accurate generalizations. 


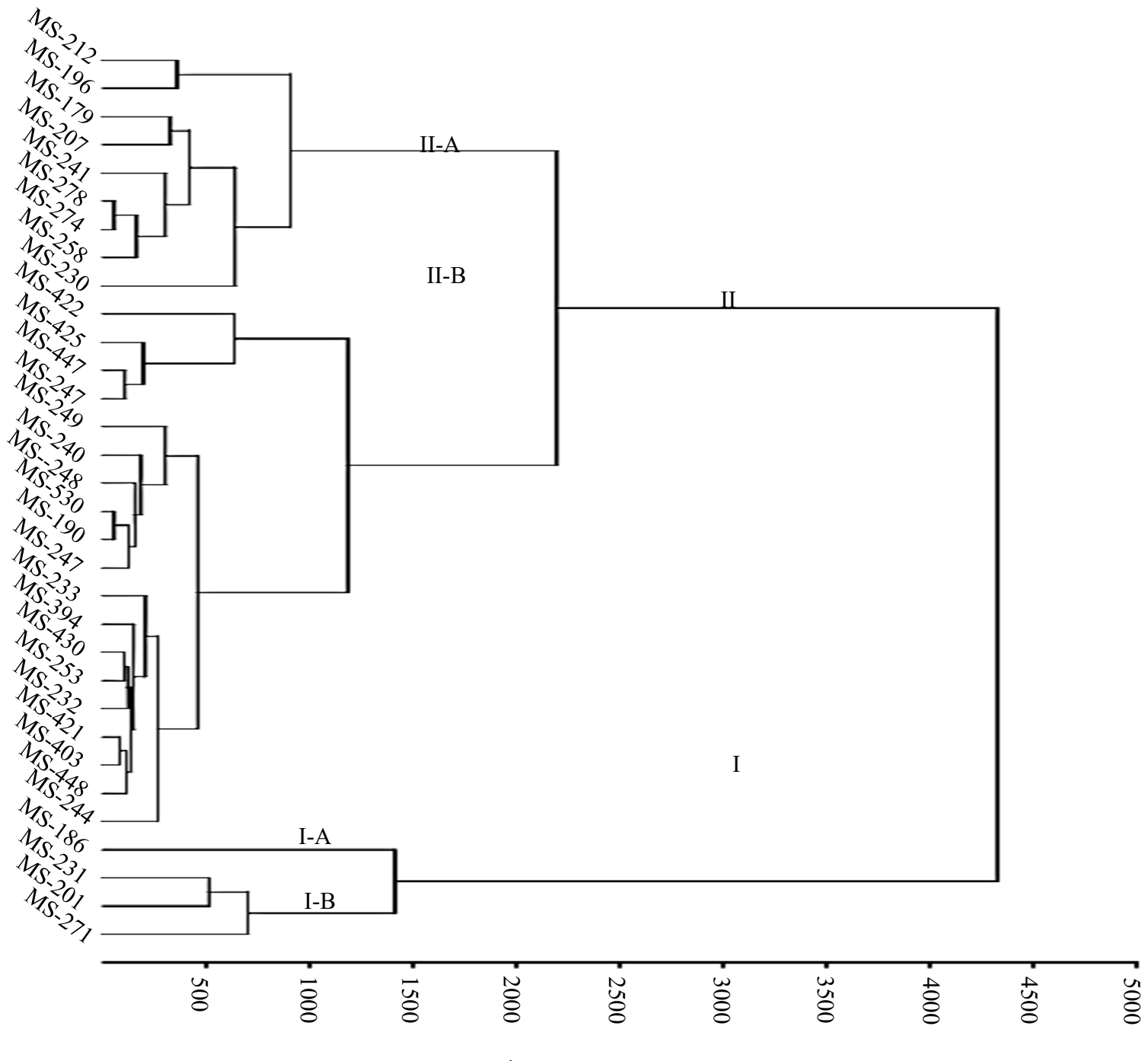

Distance

Figure 2. Dendrogram of morphological traits using unweighted pair group method with arithmetic mean (UPGMA) clustering in the selected accessions of $M$. sacchariflorus grown in the field.

\subsection{Screening of Total Phenolic Content, Total Flavonoid Content, and Antioxidant Potential in M. sacchariflorus Accessions}

The antioxidative activities of the methanolic extracts of the leaves were compared in 32 accessions of $M$. sacchariflorus. The radical scavenging effect of tested sample and standard compounds was expressed in $\mathrm{IC}_{50}$ values $\left(\mu \mathrm{g} \mathrm{mL}{ }^{-1}\right)$. It is calculated as the amount of antioxidants required to reduce the initial radical concentration by $50 \%$. Thus, the lower $\mathrm{IC}_{50}$ value, the higher the antioxidant activity. DPPH scavenging analysis revealed significant differences among the studied accessions (Table 5). DPPH scavenging potential of the leaf extracts for all of the accessions ranged from $28.85 \pm 1.53 \mu \mathrm{g} \mathrm{mL}^{-1}$ in MS-447 to $99.25 \pm 1.63 \mu \mathrm{g} \mathrm{mL} \mathrm{m}^{-1}$ in MS-190. A wide range of variation in DPPH scavenging properties was observed in Korean accessions, which ranged from $28.85 \pm 1.53$ to $91.47 \pm 3.06 \mu \mathrm{g} \mathrm{mL}^{-1}$. Based on DPPH scavenging assay, MS-279, MS-448, MS-240 accessions showed higher ability to scavenge DPPH radical than the other accessions with $\mathrm{IC}_{50}=31.55 \pm 2.01,34.26 \pm 0.94,34.45 \pm 0.80 \mu \mathrm{g} \mathrm{mL}{ }^{-1}$ for Chinese, Japanese, and Russian accessions, respectively. 
Table 5. Antioxidant activity of the selected M. sacchariflorus accessions.

\begin{tabular}{|c|c|c|c|c|}
\hline \multirow{2}{*}{ Accessions } & \multicolumn{2}{|c|}{$\mathrm{IC}_{50}\left(\mu \mathrm{g} \mathrm{mL}^{-1}\right)$} & \multirow{2}{*}{$\begin{array}{c}\text { TPC } \\
\left(\mathrm{mg} \mathrm{GAE}^{-1}\right)\end{array}$} & \multirow{2}{*}{$\begin{array}{c}\text { TFC } \\
\left(\mathrm{mg} \mathrm{QE} \mathrm{g}^{-1}\right)\end{array}$} \\
\hline & ${ }^{1} \mathrm{DPPH}$ & ABTS & & \\
\hline MS-179 & $51.36 \pm 2.46^{\mathrm{g}}$ & $48.84 \pm 0.59^{f}$ & $70.00 \pm 3.00^{r}$ & $32.28 \pm 1.20^{t}$ \\
\hline MS-196 & $88.75 \pm 0.50 \mathrm{p}$ & $72.94 \pm 2.84 \mathrm{p}$ & $32.58 \pm 2.00 \mathrm{j}$ & $18.86 \pm 1.00^{\circ}$ \\
\hline MS-212 & $67.31 \pm 1.75^{\mathrm{kl}}$ & $51.61 \pm 1.30^{g}$ & $31.36 \pm 2.00^{\mathrm{i}}$ & $13.54 \pm 1.11^{\mathrm{jkl}}$ \\
\hline MS-239 & $58.30 \pm 3.07^{\mathrm{ij}}$ & $50.71 \pm 1.35 \mathrm{fg}$ & $36.35 \pm 2.01^{1}$ & $15.7 \pm 1.01 \mathrm{mn}$ \\
\hline MS-244 & $50.23 \pm 1.30 \mathrm{~g}$ & $63.22 \pm 2.76^{\mathrm{mn}}$ & $30.23 \pm 1.01^{h}$ & $13.53 \pm 1.00 \mathrm{jkl}$ \\
\hline MS-258 & $41.50 \pm 3.12^{\mathrm{e}}$ & $25.65 \pm 2.06^{\mathrm{a}}$ & $58.49 \pm 2.90 \mathrm{p}$ & $21.56 \pm 1.50 \mathrm{p}$ \\
\hline MS-271 & $71.89 \pm 2.07^{\mathrm{m}}$ & $83.62 \pm 2.02 \mathrm{q}$ & $29.06 \pm 1.01 \mathrm{~g}$ & $12.37 \pm 1.00 \mathrm{hi}$ \\
\hline MS-279 & $31.55 \pm 2.01^{b}$ & $56.27 \pm 2.01^{\mathrm{jkl}}$ & $59.97 \pm 3.00 \mathrm{q}$ & $24.24 \pm 1.20^{q}$ \\
\hline MS-186 & $85.29 \pm 6.79^{\circ}$ & $65.96 \pm 2.28^{\circ}$ & $37.27 \pm 2.00^{\mathrm{m}}$ & $15.37 \pm 1.11^{\mathrm{m}}$ \\
\hline MS-201 & $49.60 \pm 1.81 \mathrm{~g}$ & $53.63 \pm 0.12 \mathrm{hi}$ & $48.44 \pm 2.80^{\mathrm{n}}$ & $18.59 \pm 1.10^{\circ}$ \\
\hline MS-207 & $91.47 \pm 3.06 \mathrm{q}$ & $57.62 \pm 1.39 \mathrm{kl}$ & $32.49 \pm 2.90^{j}$ & $12.96 \pm 1.12^{\mathrm{ij}}$ \\
\hline MS-241 & $37.41 \pm 1.78^{\mathrm{d}}$ & $56.71 \pm 1.40^{\mathrm{jk}}$ & $34.53 \pm 2.02^{k}$ & $16.22 \pm 1.01^{\mathrm{n}}$ \\
\hline MS-247 & $45.32 \pm 2.12^{\mathrm{f}}$ & $26.48 \pm 2.39^{a b}$ & $37.56 \pm 2.50^{\mathrm{m}}$ & $15.46 \pm 1.13 \mathrm{mn}$ \\
\hline MS-274 & $31.52 \pm 3.45^{b}$ & $52.94 \pm 1.00 \mathrm{gh}$ & $81.03 \pm 4.02^{\mathrm{s}}$ & $28.81 \pm 1.50^{\mathrm{s}}$ \\
\hline MS-278 & $30.41 \pm 0.61^{b}$ & $55.11 \pm 0.96^{h i j}$ & $48.52 \pm 3.01^{\mathrm{n}}$ & $21.65 \pm 1.80^{\mathrm{p}}$ \\
\hline MS-447 & $28.85 \pm 1.53^{\mathrm{a}}$ & $51.31 \pm 1.01 \mathrm{~g}$ & $52.87 \pm 2.01^{\circ}$ & $25.39 \pm 1.90^{\mathrm{r}}$ \\
\hline MS-248 & $99.25 \pm 1.63^{\mathrm{r}}$ & $62.88 \pm 1.38^{\mathrm{m}}$ & $29.25 \pm 2.00 \mathrm{~g}$ & $11.67 \pm 1.11^{\mathrm{g}}$ \\
\hline MS-249 & $57.06 \pm 1.59 \mathrm{ij}$ & $58.61 \pm 1.35^{1}$ & $34.51 \pm 1.40^{\mathrm{k}}$ & $15.66 \pm 1.01 \mathrm{mn}$ \\
\hline MS-190 & $59.28 \pm 2.77^{j}$ & $36.82 \pm 2.67^{\mathrm{e}}$ & $28.69 \pm 2.00 \mathrm{~g}$ & $14.14 \pm 0.90^{1}$ \\
\hline MS-231 & $44.38 \pm 1.37^{\mathrm{f}}$ & $26.51 \pm 0.87^{a b}$ & $24.64 \pm 2.00^{f}$ & $10.74 \pm 0.90^{\mathrm{f}}$ \\
\hline MS-422 & $55.41 \pm 0.63^{h}$ & $29.09 \pm 1.32^{b c}$ & $21.65 \pm 1.20^{\mathrm{de}}$ & $13.02 \pm 1.00 \mathrm{ijk}$ \\
\hline MS-425 & $55.36 \pm 1.31^{h}$ & $28.17 \pm 1.40^{\mathrm{ab}}$ & $22.3 \pm 1.20^{\mathrm{e}}$ & $12.19 \pm 1.00 \mathrm{ghi}$ \\
\hline MS-448 & $34.26 \pm 0.94^{\mathrm{c}}$ & $51.90 \pm 0.65^{\mathrm{g}}$ & $21.67 \pm 2.10^{\mathrm{de}}$ & $10.91 \pm 0.70 \mathrm{fg}$ \\
\hline MS-530 & $69.37 \pm 0.35^{1}$ & $56.02 \pm 1.28^{\mathrm{jkl}}$ & $9.97 \pm 1.30^{b}$ & $5.1 \pm 0.70 \mathrm{bc}$ \\
\hline MS-232 & $66.52 \pm 3.91^{\mathrm{k}}$ & $64.13 \pm 1.27 \mathrm{mn}$ & $6.58 \pm 0.50^{a}$ & $2.57 \pm 0.10^{\mathrm{a}}$ \\
\hline MS-233 & $77.31 \pm 2.53^{n}$ & $72.84 \pm 6.19 \mathrm{P}$ & $11.98 \pm 1.20^{\mathrm{cd}}$ & $5.11 \pm 0.10^{b c}$ \\
\hline MS-253 & $41.99 \pm 1.48^{\mathrm{e}}$ & $31.24 \pm 0.64^{\mathrm{cd}}$ & $21.04 \pm 1.011^{\mathrm{e}}$ & $9.84 \pm 1.00^{\mathrm{e}}$ \\
\hline MS-240 & $34.45 \pm 0.80^{\mathrm{cd}}$ & $52.52 \pm 1.35 \mathrm{gh}$ & $21.77 \pm 2.03^{\mathrm{de}}$ & $13.8 \pm 1.10^{\mathrm{kl}}$ \\
\hline MS-394 & $56.48 \pm 7.64 \mathrm{hi}$ & $58.59 \pm 0.81^{1}$ & $11.9 \pm 1.00^{\mathrm{cd}}$ & $6.64 \pm 0.50^{d}$ \\
\hline MS-403 & $71.83 \pm 10.45^{\mathrm{m}}$ & $31.75 \pm 0.89 \mathrm{~d}$ & $12.49 \pm 1.20^{\mathrm{d}}$ & $5.73 \pm 1.00^{\mathrm{c}}$ \\
\hline MS-421 & $90.06 \pm 2.80 \mathrm{q}$ & $35.69 \pm 3.26^{\mathrm{e}}$ & $11.3 \pm 1.00^{\mathrm{c}}$ & $4.06 \pm 1.10^{b}$ \\
\hline MS-430 & $54.53 \pm 1.38^{h}$ & $28.37 \pm 1.79^{a b}$ & $12.67 \pm 1.10^{\mathrm{d}}$ & $5.13 \pm 1.00^{b c}$ \\
\hline
\end{tabular}

${ }^{1}$ DPPH: 1,1-diphenyl-2-picrylhydrazyl, ABTS: 2,2'-azinobis 3-ethylbenzothiazoline-6-sulfonate, TPC: total phenolic content, TFC: total flavonoid content. $\mathrm{IC}_{50}=$ inhibition concentration $50 \%$. The values of individual compounds were with the mean \pm standard deviation $(n=3)$. Data having the same letter in a column were not significantly differed by Duncan's multiple comparison test $(p<0.05)$.

The antioxidant activity measured via ABTS radicals showed great amplitude among the studied accessions of M. sacchariflorus. Based on ABTS scavenging assay, MS-247, MS-448, MS-240 accessions showed higher ability to scavenge ABTS radical than the other accessions with $\mathrm{IC}_{50}=26.48 \pm 2.39,26.51 \pm 0.87,28.37 \pm 1.79 \mu \mathrm{g} \mathrm{mL}{ }^{-1}$ for Korean, Japanese and Russian accessions, respectively. Intriguingly, the highest ABTS scavenging activity $\left(25.65 \pm 2.06 \mu \mathrm{g} \mathrm{mL}^{-1}\right)$ and lowest ABTS scavenging activity $(83.62 \pm 2.02 \mu \mathrm{g} \mathrm{mL}-1)$ were both observed in Chinese accessions (MS-258 and MS-271, respectively). The total phenolic contents varied across accessions and ranged from $6.58 \pm 0.50 \mathrm{mg} \mathrm{GAE} \mathrm{g}^{-1}$ for MS-232 to $81.03 \pm 4.02 \mathrm{mg} \mathrm{GAE} \mathrm{g}^{-1}$ of dry material for MS-274. Similarly, the highest total flavonoid content was detected at $32.28 \pm 1.20 \mathrm{mg}$ quercetin (QE) $\mathrm{g}^{-1}$ (MS-179) and the lowest total flavonoid content was observed at $2.57 \pm 0.10 \mathrm{mg} \mathrm{QE} \mathrm{g}^{-1}$ (MS-232). The average content of both total phenolic content (TPC; ranging from $6.58 \pm 0.50$ to $21.77 \pm 2.03 \mathrm{mg} \mathrm{GAE} \mathrm{g}^{-1}$ ) and total flavonoid content (TFC; $2.57 \pm 0.10$ to $9.84 \pm 1.00 \mathrm{mg} \mathrm{QE} \mathrm{g}^{-1}$ ) was higher in Korean accessions. However, in Russian accessions, both the TPC and TFC were significantly lower than in accessions from other regions. Some M. sacchariflorus accessions such as MS-279 and MS-274 contained higher concentrations of TPC and TFC and showed higher DPPH radical scavenging activities, whereas others (MS-232) contained lower TPC 
and TFC and showed weak antioxidant properties, indicating that phenolic compounds significantly contributed to antioxidant activity in the MS accessions. In contrast, MS-241 and MS-231 recorded similar concentrations of TPC and TFC, but varied significantly in their antioxidant properties. The MS accessions MS-422, MS-425, and MS-430 exhibited similar antioxidant properties, but contained significantly different amounts of TPC and TFC. These findings indicate that other phytochemicals contribute to the antioxidant properties of $M$. sacchariflorus accessions, in addition to the antioxidant capacity of the phenolic compounds.

\subsection{Identification and Quantification of Phenolic Compounds in M. sacchariflorus by LC-MS/MS Analysis}

M. sacchariflorus has a wide geographical range, which results in variations in polyphenols and biological activity. However, to date, polyphenol profiles of MS accessions from different geographical regions have not been constructed. TPC assay using the Folin-Ciocalteu reagent is an indirect method of measuring the phenolic content in plant samples, and non-phenolic compounds, such as sugar and amino acids in the sample may interfere with the results. In this study, 22 polyphenol compositions and concentrations obtained from 32 accessions of $M$. sacchariflorus were analyzed using HPLC-MS/MS (Tables 6 and 7). The representative chromatogram shows distinct variation in phenolic compounds across all accessions. The peaks of the phenolic compounds depicted in the chromatogram were identified through comparison with the retention time of standard compounds. The concentrations of the phenolic compounds present in the sample were determined on the basis of the peak area (Figure 3). As shown in the results, significant variations $(p<0.05)$ in the phenolic compound concentrations and composition were observed among different $M$. sacchariflorus accessions. Twenty-two different phenolic compounds were tentatively identified and quantified; among these, protocatechuic acid, gentisic acid, $p$-hydroxybenzoic acid, chlorogenic acid, $p$-coumaric acid, ferulic acid, $m$-coumaric acid, 2,4dihydroxybenzoic acid, luteolin, and vitexin were the predominant compounds detected. Other phenolic compounds, such as orientin, apigenin, rutin, and veratric acid contributed significantly to the total phenolic compound concentration, but were not present in all of the accessions. Among the studied accessions, MS-244 yielded the highest total phenolic compound concentration ( $4415.21 \pm \mu \mathrm{g} \mathrm{mL}^{-1}$ dry weight) owing to its high concentrations of salicylic acid $\left(24.63 \pm 3.35 \mu \mathrm{g} \mathrm{mL}{ }^{-1} \mathrm{DW}\right)$, vitexin $\left(228.24 \pm 6.06 \mu \mathrm{g} \mathrm{mL}{ }^{-1} \mathrm{DW}\right)$, luteolin $\left(734.67 \pm 22.18 \mu \mathrm{g} \mathrm{mL}^{-1} \mathrm{DW}\right)$, L-phenylalanine $\left(1890.68 \pm 70.59 \mu \mathrm{g} \mathrm{mL}^{-1} \mathrm{DW}\right)$, rutin $\left(174.89 \pm 6.88 \mu \mathrm{g} \mathrm{mL}{ }^{-1} \mathrm{DW}\right)$, and chlorogenic acid $\left(326.33 \pm 11.59 \mu \mathrm{g} \mathrm{mL}^{-1} \mathrm{DW}\right)$. The concentration of L-phenylalanine was found to represent up to $42.82 \%$ of the total phenolic compound concentration in the MS-244 leaf extracts. Accession MS-448 yielded the lowest total phenolic compound concentration $\left(759.86 \mu \mathrm{g} \mathrm{mL}{ }^{-1} \mathrm{DW}\right)$. Chlorogenic acid was the most dominant phenolic acid detected in all the accessions, where it ranged from $33.63 \pm 0.55 \mu \mathrm{g} \mathrm{mL}^{-1} \mathrm{DW}$ to $455.67 \pm 8.15 \mu \mathrm{g} \mathrm{mL}{ }^{-1} \mathrm{DW}$. Homogentisic acid was recorded only in accessions MS-244 and MS-249 (4.17 \pm 0.05 and $4.10 \pm 0.15 \mu \mathrm{g} \mathrm{mL}{ }^{-1} \mathrm{DW}$, respectively). Vanillic acid was present only in accessions MS-394 and MS-421 (174.22 \pm 13.84 and $238.18 \pm 24.33 \mu \mathrm{g} \mathrm{mL}{ }^{-1} \mathrm{DW}$, respectively). Some phenolic compounds, such as rutin and quercetin, were not detected in the majority of the Russian, Japanese, and Chinese accessions. Other phenolic compounds including protocatechuic acid, $p$-hydroxybenzoic acid, $p$-coumaric acid, and ferulic acid were found at comparatively higher concentrations in the majority of the Russian accessions, illustrating the accession-specific characteristics of the studied compounds. It is therefore likely that significant genetic variation in the accessions may result in different pathways or mechanisms for the accumulation of phenolic compounds. The phenolic compounds chlorogenic acid (MS-239, $455.67 \pm 8.15$, $\left.\mu \mathrm{g} \mathrm{mL}{ }^{-1} \mathrm{DW}\right), m$-coumaric acid (MS-239, $\left.21.79 \pm 1.64, \mu \mathrm{g} \mathrm{mL}{ }^{-1} \mathrm{DW}\right)$, rutin (MS-244, $\left.174.89 \pm 6.88^{\prime} \mu \mathrm{g} \mathrm{mL}^{-1} \mathrm{DW}\right)$, and L-phenylalanine (MS-244, $\left.1890.68 \pm 70.59, \mu \mathrm{g} \mathrm{mL} \mathrm{mL}^{-1} \mathrm{DW}\right)$ were significantly higher in Chinese accessions. Among the 32 accessions, orientin (ranging from $91.47 \pm 3.13$ to $512.71 \pm 3.09, \mu \mathrm{g} \mathrm{mL}{ }^{-1} \mathrm{DW}$ ) showed the highest degree of variation 
in the Korean accessions. In contrast, the concentrations of $m$-coumaric acid, ferulic acid, $p$-coumaric acid, and protocatechuic acid were far less varied in the Korean accessions.

The phenolic compounds protocatechuic acid (MS-394, $105.67 \pm 4.93 \mu \mathrm{g} \mathrm{mL}^{-1} \mathrm{DW}$ ), p-hydroxybenzoic acid (MS-232, $171.33 \pm 2.08 \mu \mathrm{g} \mathrm{mL}{ }^{-1} \mathrm{DW}$ ), $p$-coumaric acid (MS-232, $433.33 \pm 17.67 \mu \mathrm{g} \mathrm{mL}^{-1} \mathrm{DW}$ ), ferulic acid (MS-421, $86.43 \pm 1.50 \mu \mathrm{g} \mathrm{mL}^{-1} \mathrm{DW}$ ), caffeic acid (MS-253, $56.89 \pm 2.32 \mu \mathrm{g} \mathrm{mL}{ }^{-1} \mathrm{DW}$ ), and apigenin (MS-233, $17.57 \pm 0.49 \mu \mathrm{g} \mathrm{mL}^{-1} \mathrm{DW}$ ) were significantly higher in the Russian accessions. Our findings indicate that the biochemical properties of MS accessions can be used to further improve the MS hybridization program and aid in obtaining new varieties with desirable levels of phenolic compounds.

Table 6. LC-MS/MS parameters for quantitative analysis of 22 phenolic compounds.

\begin{tabular}{|c|c|c|c|c|c|c|c|c|}
\hline Compounds & ${ }^{1} \mathrm{RT}$ & Q1 $(m / z)^{a}$ & $\mathrm{Q} 3(m / z)^{\mathrm{b}}$ & $\mathrm{DP}(\mathrm{V})^{\mathrm{c}}$ & $E P(V)^{d}$ & $\operatorname{CEP}(V)^{e}$ & $C E(e V)^{f}$ & CXP (V) ${ }^{g}$ \\
\hline Gallic acid & 5.92 & 169.056 & 125.000 & -26.000 & -10.000 & -8.000 & -20.000 & -6.000 \\
\hline Protocatechuic acid & 8.07 & 152.896 & 108.900 & -16.000 & -9.000 & -10.000 & -22.000 & -6.000 \\
\hline Gentisic acid & 10.67 & 152.871 & 107.900 & -16.000 & -8.500 & -6.000 & -28.000 & -22.000 \\
\hline$p$-hydroxybenzoic acid & 10.03 & 136.885 & 92.900 & -16.000 & -8.500 & -12.000 & -24.000 & -6.000 \\
\hline Chlorogenic acid & 8.16 & 352.846 & 191.000 & -21.000 & -7.000 & -32.000 & -30.000 & -10.000 \\
\hline$p$-coumaric acid & 11.81 & 162.866 & 118.900 & -11.000 & -7.000 & -14.000 & -20.000 & -6.000 \\
\hline Ferulic acid & 12.47 & 192.881 & 133.900 & -11.000 & -10.000 & -12.000 & -22.000 & -8.000 \\
\hline$m$-Coumaric acid & 13.04 & 162.886 & 118.900 & -21.000 & -9.000 & -8.000 & -22.000 & -4.000 \\
\hline Rutin & 10.04 & 609.002 & 299.700 & -91.000 & -10.500 & -34.000 & -52.000 & -14.000 \\
\hline Quercetin & 16.11 & 300.884 & 150.800 & -31.000 & -10.500 & -18.000 & -28.000 & -32.000 \\
\hline Kaempferol & 19.46 & 284.826 & 65.000 & -81.000 & -8.500 & -20.000 & -72.000 & -12.000 \\
\hline 2,4-dihydroxybenzoic acid & 11.54 & 152.900 & 108.900 & -21.000 & -4.500 & -10.000 & -18.000 & -6.000 \\
\hline Homogentisic acid & 7.10 & 166.920 & 122.900 & -21.000 & -7.000 & -14.000 & -14.000 & -28.000 \\
\hline Salicylic acid & 16.51 & 136.874 & 92.900 & -16.000 & -7.500 & -12.000 & -22.000 & -6.000 \\
\hline Vanillic acid & 10.46 & 166.883 & 151.900 & -11.000 & -6.500 & -10.000 & -18.000 & -32.000 \\
\hline Caffeic acid & 10.12 & 178.868 & 134.800 & -16.000 & -8.000 & -14.000 & -22.000 & -6.000 \\
\hline Orientin & 9.76 & 447.092 & 327.000 & -61.000 & -11.000 & -20.000 & -22.000 & -54.000 \\
\hline Vitexin & 10.28 & 430.826 & 310.800 & -56.000 & -9.000 & -28.000 & -22.000 & -50.000 \\
\hline Apigenin & 18.59 & 268.948 & 117.000 & -46.000 & -10.000 & -20.000 & -56.000 & -8.000 \\
\hline Luteolin & 15.73 & 284.966 & 133.200 & -66.000 & -10.000 & -16.000 & -46.000 & -30.000 \\
\hline L-Phenylalanine & 5.92 & 163.888 & 146.8 & -41.000 & -10.500 & -12.000 & -18.000 & -10.000 \\
\hline Veratric acid & 12.96 & 180.991 & 136.900 & -16.000 & -7.500 & -12.000 & -18.000 & -8.000 \\
\hline
\end{tabular}

${ }^{a}$ Precursor ion $(\mathrm{Q} 1, \mathrm{~m} / \mathrm{z}) ;{ }^{\mathrm{b}}$ fragment ion $(\mathrm{Q} 3, \mathrm{~m} / \mathrm{z}) ;{ }^{\mathrm{c}} \mathrm{DP}$ : declustering potential; ${ }^{\mathrm{d}}$ EP: entrance potential; ${ }^{\mathrm{f}} \mathrm{CEP}$ : cell entrance potential; ${ }^{\mathrm{e}} \mathrm{CE}$ : collision energy; ${ }^{\mathrm{g}} \mathrm{CXP}$ : collision cell exit potential. ${ }^{1} \mathrm{RT}$ : retention time. 
Table 7. Distribution of total phenolic compounds in selected M. sacchariflorus accessions.

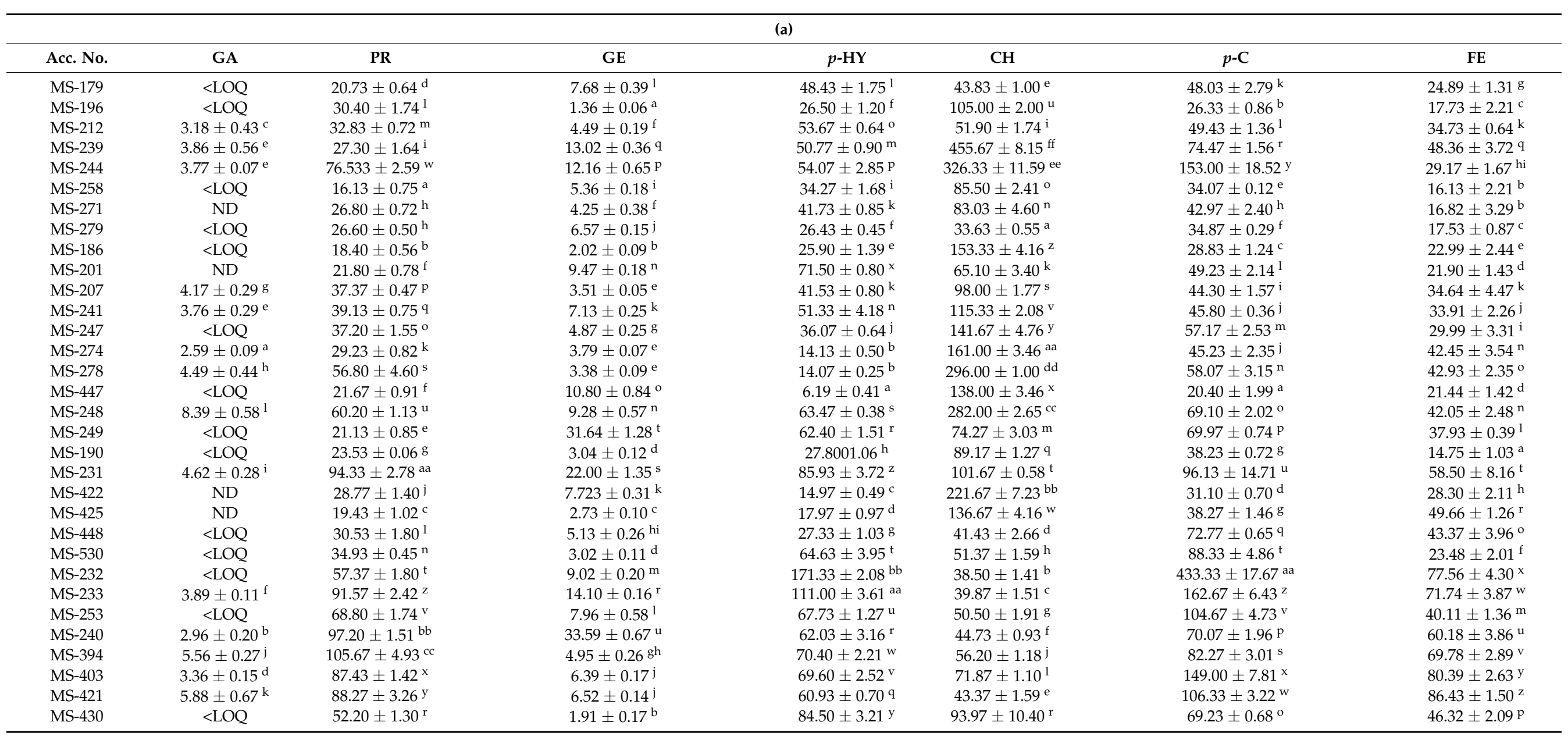


Table 7. Cont.

\begin{tabular}{|c|c|c|c|c|c|c|c|c|c|}
\hline \multicolumn{10}{|c|}{ (b) } \\
\hline Acc. No. & 2,4-DHBA & HO & SA & $\mathrm{V}$ & $\mathrm{CA}$ & $m-\mathrm{C}$ & RU & $\mathrm{QU}$ & KA \\
\hline MS-179 & $2.53 \pm 0.03^{c}$ & $<\mathrm{LOQ}^{1}$ & $4.27 \pm 0.07^{1}$ & $\mathrm{ND}^{3}$ & $4.54 \pm 0.25^{\mathrm{h}}$ & $9.16 \pm 0.35^{\mathrm{h}}$ & $25.31 \pm 0.95^{\mathrm{g}}$ & $<\mathrm{LOQ}$ & $213.36 \pm 14.03 p$ \\
\hline MS-196 & $<\mathrm{LOQ}$ & $<\mathrm{LOQ}$ & $6.02 \pm 0.12^{\circ}$ & ND & $0.95 \pm 0.07^{a}$ & $5.12 \pm 0.35$ de & ND & $\mathrm{ND}$ & $71.89 \pm 5.56^{\mathrm{h}}$ \\
\hline MS-239 & $9.17 \pm 0.28^{n}$ & $<\mathrm{LOQ}$ & $13.61 \pm 0.44^{\mathrm{w}}$ & ND & $8.92 \pm 0.24^{\mathrm{k}}$ & $21.79 \pm 1.64^{\mathrm{m}}$ & $56.43 \pm 0.91^{1}$ & $4.84 \pm 0.29^{b}$ & $<\operatorname{LOD}^{3}$ \\
\hline MS-244 & $16.48 \pm 0.99^{\mathrm{s}}$ & $4.17 \pm 0.0^{\mathrm{a}}$ & $24.63 \pm 3.35^{x}$ & ND & $2.70 \pm 0.45^{\mathrm{e}}$ & $17.65 \pm 2.43^{1}$ & $174.89 \pm 6.88^{\mathrm{m}}$ & $60.31 \pm 6.39^{d}$ & $<\mathrm{LOQ}$ \\
\hline MS-258 & $4.66 \pm 0.18^{g}$ & $<\mathrm{LOQ}$ & $3.91 \pm 0.10^{\mathrm{k}}$ & ND & $4.08 \pm 0.19^{g}$ & $6.99 \pm 0.88^{\mathrm{fg}}$ & $17.28 \pm 0.71^{b c}$ & ND & $48.18 \pm 4.31^{f}$ \\
\hline MS-271 & $4.26 \pm 0.17^{\mathrm{f}}$ & $<\mathrm{LOQ}$ & $5.18 \pm 0.34^{\mathrm{m}}$ & ND & $3.32 \pm 0.17^{\mathrm{f}}$ & $7.99 \pm 0.36 \mathrm{gh}$ & $19.52 \pm 0.15^{\mathrm{d}}$ & ND & $110.35 \pm 1.03^{k}$ \\
\hline MS-186 & $1.25 \pm 0.11^{\mathrm{a}}$ & $<\mathrm{LOQ}$ & $8.44 \pm 0.16^{\mathrm{u}}$ & ND & $2.37 \pm 0.11^{\mathrm{cd}}$ & $6.97 \pm 0.42^{f}$ & $25.48 \pm 0.30 \mathrm{gh}$ & $4.36 \pm 0.23^{c}$ & ND \\
\hline MS-201 & $2.93 \pm 0.21^{d}$ & $<\mathrm{LOQ}$ & $7.26 \pm 0.27^{r}$ & ND & $3.58 \pm 0.19^{f}$ & $15.02 \pm 0.57^{\mathrm{k}}$ & $18.53 \pm 0.45^{\mathrm{d}}$ & ND & $21.99 \pm 2.64^{b}$ \\
\hline MS-207 & $1.60 \pm 0.13^{b}$ & $<\mathrm{LOQ}$ & $6.53 \pm 0.27 p$ & ND & $2.15 \pm 0.28^{c}$ & $10.79 \pm 0.62^{i}$ & $26.47 \pm 0.67 \mathrm{gh}$ & $<\mathrm{LOQ}$ & $<\mathrm{LOQ}$ \\
\hline MS-241 & $5.81 \pm 0.18^{j}$ & $<\mathrm{LOQ}$ & $5.59 \pm 0.51^{n}$ & ND & $4.11 \pm 0.33^{g}$ & $10.07 \pm 0.57^{\mathrm{i}}$ & $27.29 \pm 0.35^{\mathrm{ij}}$ & $4.914 \pm 0.12^{c}$ & $<\mathrm{LOQ}$ \\
\hline MS-247 & $5.08 \pm 0.22^{\mathrm{i}}$ & $<\mathrm{LOQ}$ & $6.54 \pm 0.17 p$ & ND & $2.52 \pm 0.14^{\mathrm{d}}$ & $10.47 \pm 0.59^{\mathrm{i}}$ & $23.54 \pm 0.53^{f}$ & $<\mathrm{LOQ}$ & $<\mathrm{LOQ}$ \\
\hline MS-274 & $4.88 \pm 0.36^{\mathrm{h}}$ & $<\mathrm{LOQ}$ & $5.14 \pm 0.13^{\mathrm{m}}$ & ND & $7.12 \pm 0.25^{j}$ & $10.95 \pm 0.27^{\mathrm{i}}$ & $23.01 \pm 0.41^{\mathrm{f}}$ & $<$ LOQ & $34.54 \pm 2.99 \mathrm{e}$ \\
\hline MS-278 & $11.89 \pm 1.34^{\mathrm{q}}$ & $<\mathrm{LOQ}$ & $1.24 \pm 0.22^{\mathrm{d}}$ & ND & $11.96 \pm 0.23^{l}$ & $5.27 \pm 0.21 \mathrm{de}$ & $27.53 \pm 0.49^{j}$ & $5.19 \pm 0.17^{c}$ & $133.30 \pm 9.88^{\mathrm{m}}$ \\
\hline MS-447 & $10.45 \pm 0.29^{\circ}$ & $<\mathrm{LOQ}$ & $<\mathrm{LOQ}$ & ND & $5.45 \pm 0.13^{\mathrm{i}}$ & $4.55 \pm 3.81^{\mathrm{abcd}}$ & $37.42 \pm 0.58^{\mathrm{k}}$ & $<$ LOQ & ND \\
\hline MS-248 & $6.73 \pm 0.17^{1}$ & $<\mathrm{LOQ}$ & $3.67 \pm 0.25^{j}$ & ND & $7.02 \pm 0.37^{\mathrm{j}}$ & $14.63 \pm 0.49 \mathrm{jk}$ & $18.14 \pm 0.67^{\mathrm{cd}}$ & $<\mathrm{LOQ}$ & $28.38 \pm 4.99^{c}$ \\
\hline MS-249 & $17.52 \pm 0.06^{\mathrm{t}}$ & $<\mathrm{LOQ}$ & $13.22 \pm 0.19^{\mathrm{v}}$ & ND & $4.79 \pm 0.28^{\mathrm{h}}$ & $15.39 \pm 0.89^{k}$ & $16.61 \pm 0.24^{b}$ & ND & $<$ LOD \\
\hline MS-231 & $8.78 \pm 0.37^{\mathrm{m}}$ & $4.10 \pm 0.1^{\mathrm{a}}$ & $7.85 \pm 0.35^{\mathrm{s}}$ & $<$ LOQ & $22.31 \pm 1.12 \mathrm{p}$ & $13.98 \pm 1.68^{j}$ & ND & ND & $60.04 \pm 5.15^{\mathrm{g}}$ \\
\hline MS-422 & $11.23 \pm 0.15^{\mathrm{p}}$ & $<\mathrm{LOQ}$ & $0.79 \pm 0.05^{b}$ & ND & $4.72 \pm 0.04^{\mathrm{h}}$ & $5.33 \pm 0.66^{\mathrm{de}}$ & ND & ND & $<$ LOD \\
\hline MS-425 & $11.88 \pm 0.34 \mathrm{q}$ & $<\mathrm{LOQ}$ & $0.49 \pm 0.06^{\mathrm{a}}$ & ND & $11.35 \pm 0.68^{1}$ & $3.98 \pm 0.12^{a b c}$ & ND & ND & $<$ LOD \\
\hline MS-448 & $6.30 \pm 0.32^{k}$ & $<\mathrm{LOQ}$ & $1.81 \pm 0.17^{\mathrm{f}}$ & $<$ LOQ & $18.45 \pm 0.62^{n}$ & $3.77 \pm 0.19^{a b}$ & ND & ND & $61.02 \pm 4.07^{\mathrm{g}}$ \\
\hline MS-530 & $6.22 \pm 0.14^{\mathrm{k}}$ & $<\mathrm{LOQ}$ & $8.39 \pm 0.07^{\mathrm{t}}$ & ND & $5.75 \pm 0.02^{\mathrm{i}}$ & $10.97 \pm 0.62^{\mathrm{i}}$ & ND & ND & $31.24 \pm 1.78^{\mathrm{d}}$ \\
\hline MS-232 & $34.15 \pm 0.53^{\mathrm{u}}$ & $<\mathrm{LOQ}$ & $6.74 \pm 0.16^{q}$ & $<\mathrm{LOQ}$ & $30.35 \pm 1.34 \mathrm{q}$ & $6.04 \pm 0.11^{\mathrm{e}}$ & ND & ND & $106.97 \pm 3.13^{j}$ \\
\hline MS-233 & $14.21 \pm 0.23^{\mathrm{r}}$ & $<\mathrm{LOQ}$ & $3.68 \pm 0.18^{j}$ & $<\mathrm{LOQ}$ & $39.58 \pm 0.30^{r}$ & $5.02 \pm 0.21 \mathrm{~cd}$ & ND & ND & $234.51 \pm 2.91 \mathrm{q}$ \\
\hline MS-253 & $4.58 \pm 0.09^{\mathrm{h}}$ & $<\mathrm{LOQ}$ & $2.48 \pm 0.17^{g}$ & $<$ LOQ & $17.17 \pm 0.99 \mathrm{~m}$ & $8.09 \pm 0.38 \mathrm{gh}$ & $18.09 \pm 0.62^{\mathrm{cd}}$ & ND & $203.76 \pm 17.13^{\circ}$ \\
\hline MS-240 & $54.26 \pm 0.80^{\mathrm{v}}$ & $<\mathrm{LOQ}$ & $7.28 \pm 0.11^{\mathrm{r}}$ & $<\mathrm{LOQ}$ & $56.89 \pm 2.32 \mathrm{w}$ & $4.79 \pm 0.25^{\mathrm{bcd}}$ & ND & ND & $239.63 \pm 2.71^{\mathrm{r}}$ \\
\hline MS-394 & $3.09 \pm 0.13^{\mathrm{d}}$ & $<\mathrm{LOQ}$ & $0.76 \pm 0.07^{b}$ & $174.22 \pm 13.0^{\mathrm{a}}$ & $52.03 \pm 0.86^{\mathrm{v}}$ & $3.64 \pm 0.18^{a}$ & ND & ND & $46.72 \pm 4.42^{\mathrm{f}}$ \\
\hline MS-403 & $5.71 \pm 0.13^{j}$ & $<\mathrm{LOQ}$ & $1.81 \pm 0.09^{\mathrm{f}}$ & $<$ LOQ & $43.47 \pm 2.15^{\mathrm{t}}$ & $4.14 \pm 0.09 \mathrm{abc}$ & ND & ND & $173.61 \pm 10.66^{n}$ \\
\hline MS-421 & $8.87 \pm 0.24^{\mathrm{m}}$ & $<$ LOQ & $1.01 \pm 0.05^{\mathrm{c}}$ & $238.18 \pm 24.0^{b}$ & $45.58 \pm 1.53^{\mathrm{u}}$ & $4.11 \pm 0.13 \mathrm{abc}$ & ND & ND & $129.55 \pm 5.89^{1}$ \\
\hline MS-430 & $3.65 \pm 0.17^{\mathrm{e}}$ & $<\mathrm{LOQ}$ & $<$ LOQ & $<$ LOQ & $20.50 \pm 1.25^{\circ}$ & $3.64 \pm 0.11^{\mathrm{a}}$ & ND & ND & $91.49 \pm 7.92^{\mathrm{i}}$ \\
\hline
\end{tabular}


Table 7. Cont.

\begin{tabular}{|c|c|c|c|c|c|c|c|}
\hline \multicolumn{8}{|c|}{ (c) } \\
\hline Acc. No. & ORE & VIT & API & LUT & L-Phe & VA & Total $\left(\mu \mathrm{g} \mathrm{g}^{-1} \mathrm{DW}\right)$ \\
\hline MS-179 & $316.99 \pm 6.69^{s}$ & $125.15 \pm 5.29$ aа & $4.55 \pm 0.27^{\mathrm{k}}$ & $175.33 \pm 5.03^{\circ}$ & $481.42 \pm 12.03^{\mathrm{k}}$ & $<$ LOQ & $1342.84^{\mathrm{k}}$ \\
\hline MS-196 & $317.36 \pm 15.95^{\mathrm{s}}$ & $57.84 \pm 0.76^{\mathrm{r}}$ & $<\mathrm{LOD}$ & $41.57 \pm 1.45^{\text {a }}$ & $447.07 \pm 24.73^{\mathrm{h}}$ & $<\mathrm{LOQ}$ & $1083.25^{\mathrm{e}}$ \\
\hline MS-212 & $240.88 \pm 6.76^{\circ}$ & $50.63 \pm 0.63 q$ & $4.37 \pm 0.40^{\mathrm{j}}$ & $230.67 \pm 0.58^{\mathrm{u}}$ & $440.78 \pm 33.31^{g}$ & $<\mathrm{LOQ}$ & $1240.52^{i}$ \\
\hline MS-239 & $116.99 \pm 1.23^{\mathrm{e}}$ & $61.49 \pm 1.61^{\mathrm{t}}$ & ND & $75.27 \pm 0.74^{\mathrm{d}}$ & $586.06 \pm 32.18^{p}$ & $<\mathrm{LOQ}$ & $1628.02^{\circ}$ \\
\hline MS-244 & $227.74 \pm 13.62^{\mathrm{m}}$ & $228.24 \pm 6.06^{\mathrm{cc}}$ & $3.55 \pm 0.69 \mathrm{~g}$ & $734.67 \pm 22.18^{\text {ee }}$ & $1890.68 \pm 70.59$ y & $374.47 \pm 52.78^{\mathrm{i}}$ & $4415.21^{\mathrm{u}}$ \\
\hline MS-258 & $164.19 \pm 2.33^{j}$ & $47.87 \pm 1.92 \mathrm{~m}$ & $2.67 \pm 0.19^{a}$ & $91.80 \pm 5.22 \mathrm{~g}$ & $530.51 \pm 18.82 \mathrm{~m}$ & $<$ LOQ & 1065.42 de \\
\hline MS-271 & $496.43 \pm 26.49^{t}$ & $226.45 \pm 13.92 \mathrm{bb}$ & $2.90 \pm 0.17^{c}$ & $94.70 \pm 2.61^{\mathrm{h}}$ & $572.32 \pm 29.69^{\circ}$ & $<$ LOQ & $1648.67^{\circ}$ \\
\hline MS-279 & $129.98 \pm 4.48^{g}$ & $22.29 \pm 1.83^{c}$ & $<\mathrm{LOD}$ & $84.27 \pm 3.41^{\mathrm{f}}$ & $349.20 \pm 31.66^{f}$ & $272.09 \pm 11.64^{\mathrm{b}}$ & $1040.62^{\mathrm{d}}$ \\
\hline MS-201 & $134.78 \pm 3.77^{\mathrm{h}}$ & $25.00 \pm 0.49^{\mathrm{e}}$ & $3.92 \pm 0.23^{i}$ & $569.67 \pm 29.37$ ee & $868.22 \pm 15.32^{\mathrm{u}}$ & $269.94 \pm 20.78^{a}$ & $2157.85^{\mathrm{t}}$ \\
\hline MS-207 & $107.66 \pm 1.10^{\mathrm{d}}$ & $42.13 \pm 0.76^{\mathrm{k}}$ & $3.14 \pm 0.17^{d}$ & $126.00 \pm 4.00^{1}$ & $828.89 \pm 7.02^{\mathrm{t}}$ & $<$ LOQ & $1418.88^{1}$ \\
\hline MS-241 & $118.72 \pm 4.36^{\mathrm{f}}$ & $30.38 \pm 2.17^{g}$ & $3.92 \pm 0.16^{\mathrm{i}}$ & $240.00 \pm 15.62 \mathrm{w}$ & $476.88 \pm 68.41^{j}$ & $<\mathrm{LOQ}$ & $1224.074^{\mathrm{i}}$ \\
\hline MS-247 & $193.25 \pm 3.26^{1}$ & $60.93 \pm 1.57^{\mathrm{t}}$ & $<$ LOQ & $199.33 \pm 2.08^{\mathrm{s}}$ & $469.53 \pm 12.79^{\mathrm{i}}$ & $<\mathrm{LOQ}$ & $1278.16^{\mathrm{j}}$ \\
\hline MS-274 & $270.63 \pm 14.59^{\mathrm{r}}$ & $23.22 \pm 0.78^{\mathrm{d}}$ & $<\mathrm{LOQ}$ & $197.33 \pm 3.51^{\mathrm{r}}$ & $705.46 \pm 4.83^{\mathrm{r}}$ & $<\mathrm{LOQ}$ & $1546.16^{\mathrm{m}}$ \\
\hline MS-278 & $512.71 \pm 3.09^{\mathrm{u}}$ & $96.10 \pm 0.31^{z}$ & $10.79 \pm 0.23^{x}$ & $409.33 \pm 3.32^{c c}$ & $<\mathrm{LOQ}$ & $384.38 \pm 5.14^{\mathrm{k}}$ & $1952.13^{\mathrm{r}}$ \\
\hline MS-447 & $130.34 \pm 7.25 \mathrm{~g}$ & $34.99 \pm 0.87^{h}$ & $3.44 \pm 0.26^{\mathrm{f}}$ & $239.00 \pm 3.00^{\mathrm{v}}$ & $<$ LOQ & $<$ LOQ & $684.14^{\mathrm{a}}$ \\
\hline MS-248 & $119.24 \pm 3.78^{\mathrm{f}}$ & $26.49 \pm 1.14^{\mathrm{f}}$ & $3.17 \pm 0.09^{\mathrm{e}}$ & $375.33 \pm 6.03^{\mathrm{bb}}$ & $743.37 \pm 38.07^{\mathrm{s}}$ & $<\mathrm{LOQ}$ & $1852.28 \mathrm{q}$ \\
\hline MS-249 & $192.60 \pm 10.56^{1}$ & $34.51 \pm 1.05^{h}$ & $<\mathrm{LOQ}$ & $98.67 \pm 1.53^{\mathrm{i}}$ & $985.37 \pm 23.54^{x}$ & $406.22 \pm 25.08^{1}$ & $2082.24^{\mathrm{s}}$ \\
\hline MS-190 & $<$ LOQ & $48.08 \pm 1.96^{n}$ & $<$ LOQ & $119.67 \pm 5.51^{\mathrm{k}}$ & $655.35 \pm 51.96 \mathrm{q}$ & $277.02 \pm 7.49^{c}$ & $1309.53^{j k}$ \\
\hline MS-422 & $<$ LOQ & $67.47 \pm 1.08^{u}$ & $5.61 \pm 0.21^{1}$ & $323.67 \pm 8.39^{z}$ & $284.15 \pm 17.81^{\mathrm{e}}$ & $471.81 \pm 7.72 \mathrm{~m}$ & $1507.31 \mathrm{~m}$ \\
\hline MS-425 & $170.58 \pm 7.16^{\mathrm{k}}$ & $90.69 \pm 4.32 \mathrm{y}$ & $6.74 \pm 0.29^{\mathrm{r}}$ & $289.33 \pm 4.51$ y & $<$ LOQ & $283.69 \pm 12.55^{\mathrm{e}}$ & $1133.46^{\text {fgh }}$ \\
\hline MS-448 & $139.18 \pm 5.64^{j}$ & $19.75 \pm 0.79^{\mathrm{a}}$ & $6.71 \pm 0.29 \mathrm{q}$ & $343.33 \pm 6.66^{\text {aa }}$ & $<\mathrm{LOQ}$ & $<\mathrm{LOQ}$ & $759.86^{b}$ \\
\hline MS-530 & $234.28 \pm 8.07^{n}$ & $39.19 \pm 0.95^{j}$ & $7.78 \pm 0.58^{v}$ & $225.67 \pm 6.67^{t}$ & $490.27 \pm 12.20^{1}$ & $306.59 \pm 11.88^{g}$ & $1600.87^{n}$ \\
\hline MS-232 & $134.19 \pm 5.02^{h}$ & $84.16 \pm 3.67^{w}$ & $6.94 \pm 0.26^{\mathrm{t}}$ & $76.07 \pm 0.76^{\mathrm{e}}$ & $257.36 \pm 2.97^{d}$ & $350.34 \pm 30.59^{\mathrm{h}}$ & $1773.45^{\mathrm{p}}$ \\
\hline MS-233 & $136.52 \pm 6.26^{\mathrm{i}}$ & $34.55 \pm 0.41^{h}$ & $17.57 \pm 0.49^{z}$ & $158.00 \pm 1.00^{n}$ & $255.34 \pm 31.66^{c}$ & $<$ LOQ & 1159.31 ghi \\
\hline MS-253 & $263.30 \pm 13.26^{p}$ & $49.57 \pm 0.71^{\circ}$ & $6.40 \pm 0.42^{\circ}$ & $176.00 \pm 7.94 \mathrm{p}$ & $240.25 \pm 27.52^{b}$ & $<\mathrm{LOQ}$ & $1125.70 \mathrm{fg}$ \\
\hline MS-240 & $354.55 \pm 15.81^{t}$ & $86.63 \pm 5.04^{x}$ & $6.44 \pm 0.18^{p}$ & $249.67 \pm 4.16^{x}$ & $<\mathrm{LOQ}$ & $<$ LOQ & $1191.27^{\mathrm{i}}$ \\
\hline MS-394 & $104.16 \pm 3.46^{c}$ & $30.15 \pm 0.88^{g}$ & $6.19 \pm 0.15^{n}$ & $52.43 \pm 0.90^{c}$ & $<\mathrm{LOQ}$ & $<\mathrm{LOQ}$ & $821.50^{c}$ \\
\hline MS-403 & $120.17 \pm 6.81^{g}$ & $36.13 \pm 0.63^{i}$ & $7.21 \pm 0.11^{\mathrm{u}}$ & $105.33 \pm 3.22^{j}$ & $<\mathrm{LOQ}$ & $282.27 \pm 7.08^{\mathrm{d}}$ & $1074.28^{\mathrm{e}}$ \\
\hline MS-421 & $133.100 \pm 1.465^{\mathrm{h}}$ & $26.89 \pm 0.69^{\mathrm{f}}$ & $6.89 \pm 0.26 \mathrm{~s}$ & $47.53 \pm 0.90^{\mathrm{b}}$ & $201.40 \pm 13.09^{a}$ & $<\mathrm{LOQ}$ & 1111.29 ef \\
\hline MS-430 & $266.31 \pm 11.99 q$ & $74.69 \pm 4.30^{v}$ & $5.88 \pm 0.16^{\mathrm{m}}$ & $148.67 \pm 2.89^{\mathrm{m}}$ & $<$ LOQ & $298.97 \pm 6.56^{f}$ & 1170.44 ghi \\
\hline
\end{tabular}

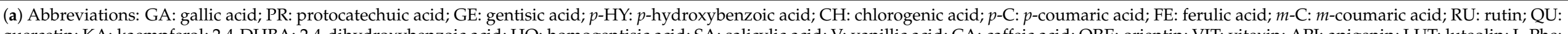

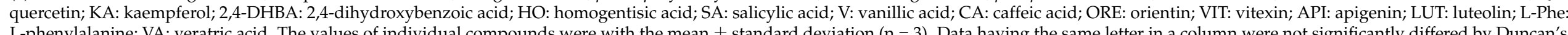

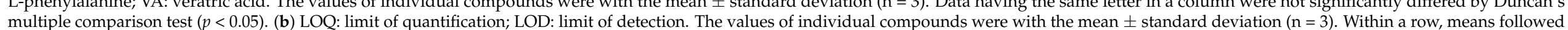

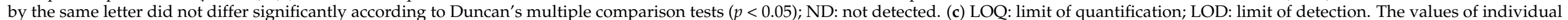
compounds were with the mean \pm standard deviation $(n=3)$. Within a row, means followed by the same letter did not differ significantly according to Duncan's multiple comparison tests $(p<0.05)$. 


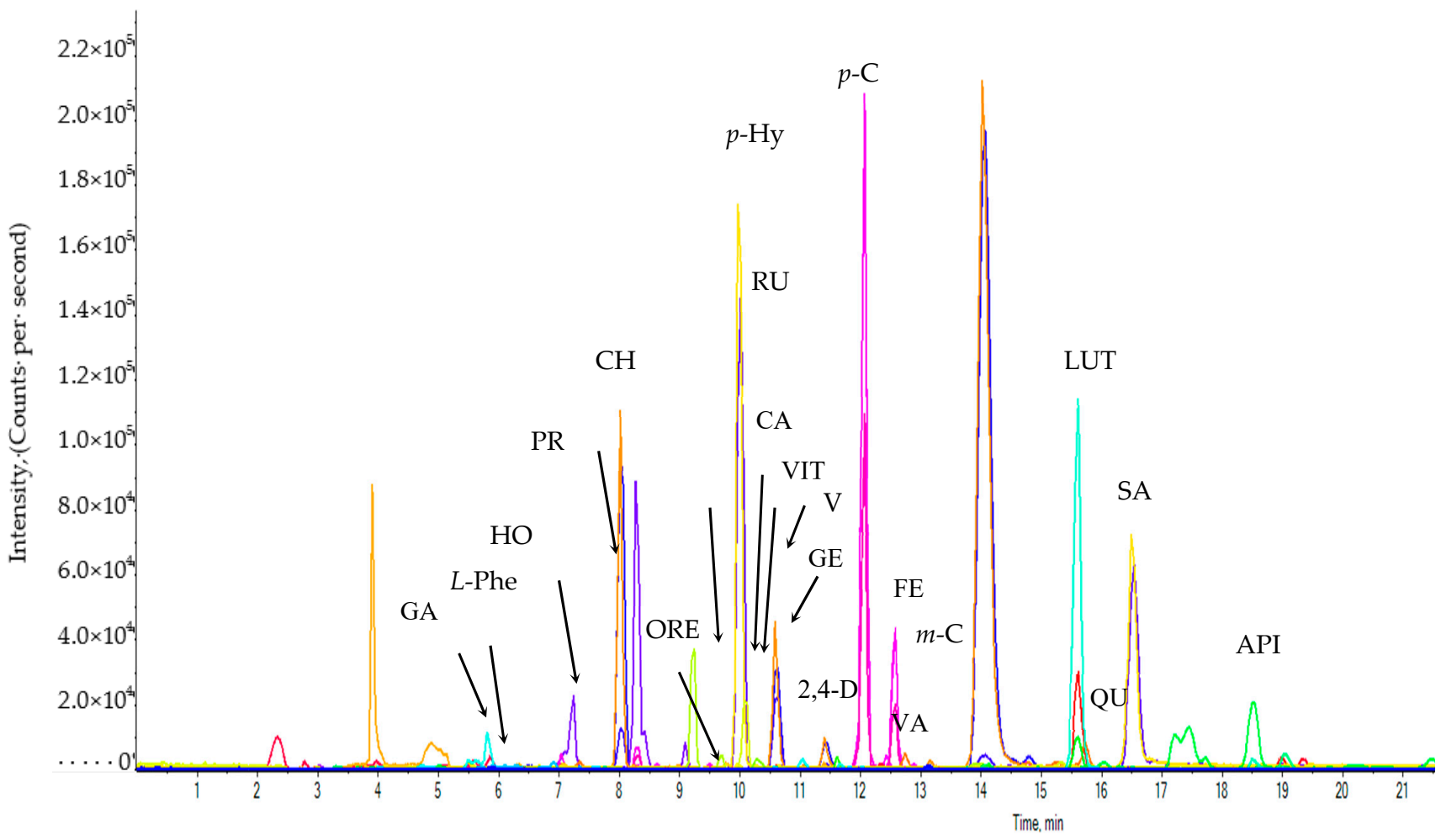

Figure 3. Representative multiple reaction monitoring mode (MRM) ion chromatogram of MS-448 accession. GA: gallic acid; PR: protocatechuic acid; GE: gentisic acid; $p$-HY: $p$-hydroxybenzoic acid; $\mathrm{CH}$ : chlorogenic acid; $p$-C: $p$-coumaric acid; FE: ferulic acid; $m$-C: $m$-coumaric acid; RU: rutin; QU: quercetin; KA: kaempferol; 2,4-DHBA: 2,4-dihydroxybenzoic acid; HO: homogentisic acid; SA: salicylic acid; V: vanillic acid; CA: caffeic acid; ORE: orientin; VIT: vitexin; API: apigenin; LUT: luteolin; L-Phe: L-phenylalanine; VA: veratric acid.

3.3.1. Pearson's Correlation Analysis between Antioxidant Activities and Phenolic Compounds

Pearson's correlation analysis showed significant and positive correlations between antioxidant activities and total phenolic content, as well as total flavonoid content, both of which varied widely among the four geographical study regions (Table 8). Samples with lower RC50 values displayed higher scavenging activity, as a lower amount of antioxidant was required to inhibit or scavenge $50 \%$ of the radicals in the reaction. Therefore, when determining the correlation value, we correlated the $1 / \mathrm{RC} 50$ value in DPPH with the phenolic compounds. Strong and positive associations were observed between DPPH and total phenolic content and total flavonoid content $(r=0.848$ and $r=0.915$, respectively, $p<0.05$ ) in the Russian accessions and Chinese accessions (between DPPH and TPC, $r=0.907, p<0.05$; and between ABTS and TFC, $r=0.895, p<0.05)$. In contrast, the correlations between these parameters were slightly lower in the Japanese accessions and in the Korean accessions, suggesting that both TPC and TFC contributed significantly to the antioxidant properties of the MS accessions. Moreover, in this study, significant, moderately positive correlations were observed between DPPH scavenging activity and gentisic acid, $p$-hydroxybenzoic acid, chlorogenic acid, $p$-coumaric acid, rutin, and quercetin $(r=0.385$, $r=0.379, r=0.362, r=0.353, r=0.490$, and $r=0.372$, respectively; $p<0.05$ ) (Table S1). A significant, moderately positive correlation was observed between ABTS scavenging activity and ferulic acid $(r=0.475, p<0.05)$, further indicating that phenolic compounds are major contributors to the antioxidant potential of M. sacchariflorus. However, correlations 
between phenolic compounds and antioxidant activities could not be observed in all of the accessions.

Table 8. Pearson's correlation coefficients between the antioxidant potential, total phenolic content, and total flavonoid content in selected M. sacchariflorus accessions.

\begin{tabular}{|c|c|c|c|c|c|}
\hline Accessions & Variables & DPPH & ABTS & TPC & TFC \\
\hline \multirow{4}{*}{ Chinese accessions } & $\mathrm{DPPH}$ & 1 & 0.416 & $0.907^{* *}$ & 0.485 \\
\hline & ABTS & & 1 & 0.258 & $0.895 * *$ \\
\hline & $\mathrm{TPC}$ & & & 1 & 0.457 \\
\hline & TFC & & & & 1 \\
\hline \multirow[t]{4}{*}{ Korean accessions } & $\mathrm{DPPH}$ & 1 & 0.061 & 0.612 & $0.817^{*}$ \\
\hline & ABTS & & 1 & -0.123 & -0.153 \\
\hline & $\mathrm{TPC}$ & & & 1 & $0.929^{* *}$ \\
\hline & TFC & & & & 1 \\
\hline \multirow[t]{4}{*}{ Japanese accessions } & $\mathrm{DPPH}$ & 1 & 0.254 & 0.605 & 0.774 * \\
\hline & ABTS & & 1 & -0.072 & 0.269 \\
\hline & TPC & & & 1 & $0.921^{* *}$ \\
\hline & TFC & & & 0. & 1 \\
\hline \multirow[t]{4}{*}{ Russian accessions } & DPPH & 1 & 0.046 & $0.848^{* *}$ & $0.915^{* *}$ \\
\hline & ABTS & & 1 & 0.256 & 0.027 \\
\hline & $\mathrm{TPC}$ & & & 1 & $0.945^{* *}$ \\
\hline & TFC & & & & 1 \\
\hline
\end{tabular}

\subsubsection{Principal Components Analysis (PCA) of Phenolic Compounds}

PCA was used to reduce the dimensions and to establish the relationships between 22 phenolic compounds and the antioxidant capacity of the 32 accessions of MS (Figure 4). The first and second principal components scored $22.45 \%$ and $18.59 \%$ of the total variance, respectively. Along axis 1 of the PCA analysis, the Russian accessions formed a clear group on the positive side and were associated with the phenolic compounds caffeic acid, ferulic acid, apigenin, $p$-hydroxybenzoic acid, 2,4-dihydroxybenzoic acid, gallic acid, protocatechuic acid, kaempferol, and vanillic acid. Two Korean accessions (MS278, MS-447) and one Japanese accession (MS-198) contributed in the negative region of axis 1 (PC1) and were related to the phenolic components such as L-phenylalanine, $m$-coumaric acid, chlorogenic acid, rutin, salicylic acid, vitexin, quercetin, orientin, veratric acid, homogentisic acid, gentisic acid, $p$-coumaric acid, and to the antioxidant properties (DPPH). Along axis 2 of the PCA analysis, four accessions (MS-179, MS-425, MS-430, and MS-448) were associated with higher antioxidant properties (ABTS). None of the quantitative characters contributed to the remaining accessions, which formed a separate group in the negative region of axis II (PC2). These results suggest that the phenolic compound profiles of $M$. sacchariflorus could be used as a potential biomarker for the study of its biodiversity. 


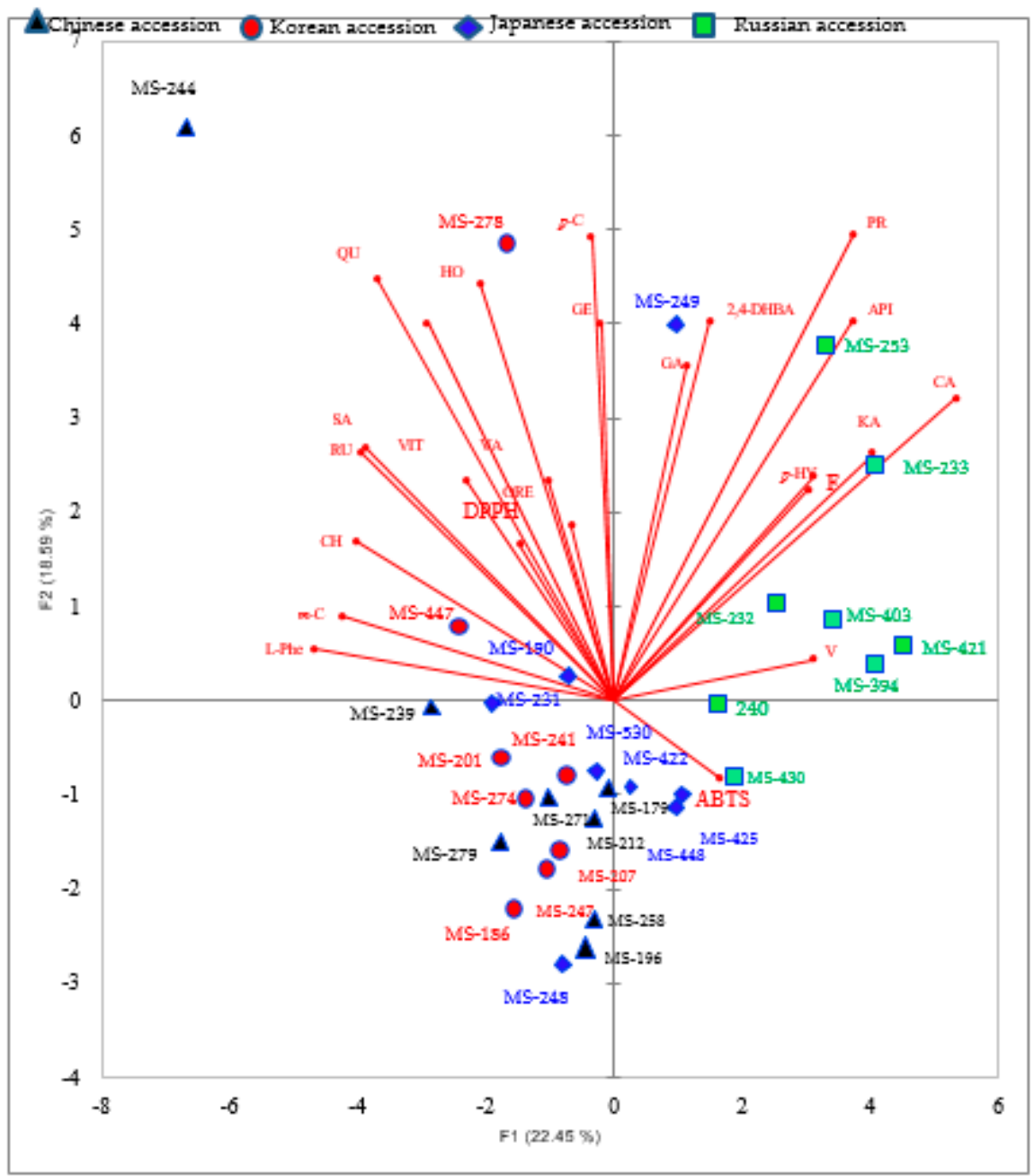

Figure 4. Principal composition analysis (PCA) biplot constructed by plotting the PC1 (vertical axis) scores against the PC2 (horizontal axis) scores obtained from phenolic compounds and antioxidant activity.

\subsubsection{UPGMA Cluster Analysis Using Phytochemicals}

A dendrogram of $32 \mathrm{M}$. sacchariflorus accessions was prepared based on the phytochemical and antioxidant properties of the accessions. As is evident from the results, the 32 accessions of $M$. sacchariflorus formed two major groups (Figure 5). Group A consists of a single accession (MS-244), whereas the remainder of the accessions formed group B. Group B is further divided into two sub-clusters: subgroup I contains a single accession (MS-278), and the remainder of the accessions comprise subgroup II. 


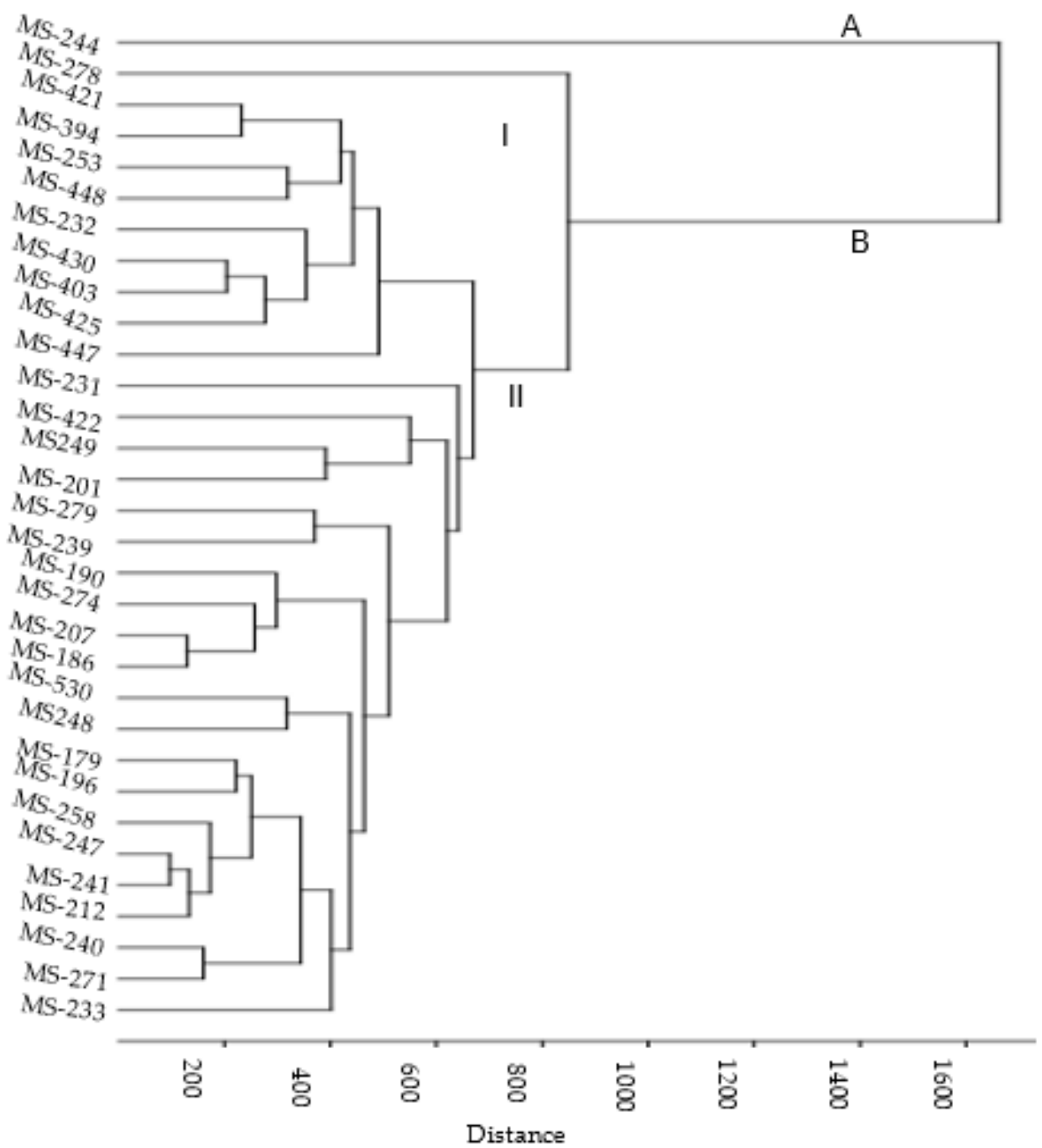

Figure 5. Dendrogram of morphological traits using UPGMA clustering in the selected accessions of M. sacchariflorus based on phenolic compounds.

\section{Discussion}

\subsection{Morphological Traits in M. sacchariflorus Accessions}

Proper knowledge of the morphological diversity and phytochemical compound composition among these accessions is important for plant breeding efforts to improve the biomass and bioactive compound profile of $M$. sacchariflorus, and may also be useful for improving its biological and functional properties for human consumption [51,54]. In the present study, there was a wide range of variation in the morphological traits among the accessions originating from different geographical regions. Changes in environmental variables, such as cold and light, can trigger a series of changes in the metabolic pathways [55-57], and may play an important role during the acclimation process in plants. In this study, M. sacchariflorus was collected from different geographical origins, presumably with various adaptations to varied conditions of altitude and cold stress. Previous studies attributed the variation in morphological traits of the plant accessions to the genetic makeup of the accessions and to environmental factors [58,59]. In this study, all 32 accessions of $M$. sacchariflorus were cultivated in the same experimental field, under uniform environmental conditions. Therefore, the extant differences in their morphological traits and biochemical markers could logically be attributed to their origin or their genetic parameters. 
As revealed by ANOVA $(p<0.01$ and $p<0.05)$, the majority of the measured morphological traits showed significant variability among the studied accessions. Plant height, a primary trait for selection in plant breeding, was moderately positively correlated with culm number and biomass (fresh weight, dry weight). This result is corroborated by the work of Yan et al. [60], which reported a higher and positive correlation between plant height and tiller diameter. A similar trend was observed between biomass and tiller number in M. sacchariflorus by Yan et al. [60], indicating that these parameters (plant height, tiller number, culm number, and culm diameter) play key role in increasing biomass in M. sacchariflorus.

A wide range of variation was observed in the duration of the first heading date and $50 \%$ heading date metrics in the M. sacchariflorus accessions, indicating a high level of genetic variation controlling the flowering time in M. sacchariflorus. Moreover, in similar studies, Clifton-Brown et al. [8], Yan et al. [60], and Stewart et al. [61] observed pronounced variation in heading time, which they attributed to the adaptation of the M. sacchariflorus accessions to a wide range of latitudes and environmental stress adopted during growth and development. In the present study, the majority of the Chinese accessions showed longer periods to production of first heading date and 50\% heading date metrics. In contrast, the Russian trials displayed smaller first heading dates and $50 \%$ heading dates. Longer growing seasons and later flowering could have partially contributed to the biomass weight, as is evident by the moderate correlation between these parameters. These results are in accordance with the reports of Yan et al. [60], in which a positive correlation between biomass and flowering time was reported in accessions of $M$. sacchariflorus. Moreover, late flowering increased the biomass production in $M$. sacchariflorus, but reduced the percentage of seed setting in $M$. sacchariflorus plants $[3,10,62]$.

Winter survival rate or overwintering ability of first year M. sacchariflorus accessions was lower than in the subsequent growing seasons, with little or no damage occurring and vigorous growth. This finding is corroborated by the report of Clifton-Brown et al. [10], in which low survival rates of $M$. sacchariflorus accessions are reported in the winter. In similar studies, Clifton-Brown et al. [10] and Christian et al. [63] observed that accessions grown in the first year store less nutrients in the rhizome to survive the winter and have inadequate reserves with which to regenerate shoots in the following year. These researchers indicated that young shoots might not attain the full dormancy required for survival of the cold winter in their first year and may continue to produce young shoots. Another hypothesis indicates that cold winter temperatures may kill the tissues of the rhizome when the temperature drops below $-5{ }^{\circ} \mathrm{C}$ [63]. Yan et al. [60] found differences in the winter survival rates of accessions from southern and northern populations in China, and they attributed these variations to freezing damage during the cold winter. In the present study, the winter mortality rates for the subsequent years (second, third, and fourth year of establishment) were found to decrease with increased biomass. These results are well in accordance with the report by Riche and Christian [64], which found that higher biomass due to increased nutrients and deeper-rooted rhizomes in the older accessions of $M$. sacchariflorus likely granted greater protection from the cold temperatures and decreased the mortality rate in older rhizomes.

The UPGMA dendrogram based on 18 quantitative traits assessed in 32 accessions revealed similarities and distinctions between these traits. However, the separation of accessions was not corroborated by their geographical origin. Accessions such as MS-271 and MS-530, which have similar plant height, spring regrowth time, first heading date, 50\% heading date, first flowering date, $50 \%$ flowering date, internode length, moisture content, and CCir/Bcir, clustered into different groups. Similarly, Korean accessions such as MS-196 and MS-207, which share common traits, such as plant height, spring regrowth time, first heading date, $50 \%$ heading date, first flowering date, $50 \%$ flowering date, and culm nodes number, were associated with different groups. The clustering pattern developed from 18 morphological traits differed vastly from that obtained using phytochemical analysis. The discrepancies between the two cluster analyses indicate the existence of genetic varia- 
tion within the M. sacchariflorus accessions. Moreover, the accessions from four different geographical origins overlapped in the cluster pattern, indicating a lack of regional differentiation. Disparities between morphological and phytochemical cluster analyses were reported in other studies [52,65]. It is likely that the expression of morphological traits and the phytochemical composition of plants can be affected by the environmental conditions and their genetic traits.

\subsection{Identification and Quantification of Phenolic Compounds of M. sacchariflorus Accessions by LC-MS/MS Analysis}

The total phenolic contents and total flavonoid contents of the plant accessions may not explain the antioxidant activity of the plant extracts accurately, as the Folin-Ciocalteu method may overestimate or interfere with the evaluation of the total phenolic content, which may contain vitamins and ascorbic acids [66]. Therefore, LC-MS/MS analyses of phenolic compounds were carried out to separate and quantify the phenolic compounds in the M. sacchariflorus accessions. Significant variation of phenolic compounds composition and concentration was observed in the $M$. sacchariflorus accessions. This tremendous variation in the metabolite profiles can be attributed to the acclimation of $M$. sacchariflorus accessions to climatic conditions and stresses of their origin. Among the phenolic compounds, $p$-coumaric acid, ferulic acid, $p$-hydroxybenzoic acid, chlorogenic acid, vitexin, and luteolin were the dominant phenolic compounds and were detected in all of the accessions, albeit at different concentrations. Other phenolic compounds were detected, including derivatives of hydroxybenzoic acid, 3-feruloylquinic acid, vanillic acid, caffeic acid, pcoumaroylquinic acids, p-coumaric acid, ferulic acid, syringic acid, caffeoylshikimic acids, 5-caffeoylquinic acid, p-hydroxy benzaldehyde, and vanillin [67-69]. However, these were detected in fewer accessions of $M$. sacchariflorus, with limited or no geographical variation in the accessions. It is important to mention that this study constitutes the first report on the phenolic compound composition of $M$. sacchariflorus accessions to utilize a wide range of accessions from diverse bioclimatic origins.

\subsection{Screening of In Vitro Antioxidant Capacity in M. sacchariflorus Accessions}

Abiotic factors such as habitat, climate, and genetic makeup influence the antioxidant potential of plant species [70]. We examined the antioxidant capabilities of $M$. sacchariflorus accessions using DPPH and ABTS radical scavenging assays. The antioxidant data obtained by the two assays were notably different, but were highly correlated. There was tremendous variation in the antioxidant capacity within the accessions, with some exhibiting very high antioxidant activity that can be associated with their total phenolic and total flavonoid contents, as indicated by positive correlations. Phenolic compounds have been reported to act as antioxidants by donating hydrogen ions or electrons, chelating metal cations, or scavenging radicals [71,72]. The number of $\mathrm{OH}$ groups, arrangement of $\mathrm{OH}$ groups, availability of electron-donating and withdrawing substituents, and aromatic rings in the phenolic compounds determine the antioxidant capacity of plant extracts to a significant extent [73-75]. Other studies have pointed out that differences in genotypic and environmental factors during growth account for variation in the antioxidant potential in accessions [76-78]. Our results indicate these features are genetically controlled, because the climatic conditions were identical for all tested accessions; this indicates the utility of these accessions for plant breeding to improving traits. Moreover, a number of previous studies have attributed the antioxidant activity of some plant species to phenolic compounds including ferulic acid, $p$-coumaric acid, gentisic acid, $p$-hydroxybenzoic acid, rutin, and quercetin, which act as hydrogen donors, reducing agents, and singlet oxygen quenchers [79-88]. Some of the accessions originating from China (MS-244) exhibited exceptionally high levels of antioxidant activity and showed higher, positive correlations with phenolic compound contents. This exception could be due to higher correlation between these parameters and greater accumulations or concentrations of L-phenylalanine, luteolin, vitexin, salicylic acid, 2,4-dihydroxybenzoic acid, rutin, and quercetin in the MS-244 trials. Similarly, a positive correlation was observed between antioxidant capacity and total phenolic content 
in Miscanthus sinensis [89,90]. Our result is also consistent with other reports [76-78,91,92], which presented linear correlations between the antioxidant capacity of a plant with its varieties and concentrations of phenolic compounds. In other studies, wide variations were observed in the phenolic compounds and antioxidant potential of plant accessions collected from different geographic locations, and were attributed to the variation in the genetic makeup necessary to adapt to new climatic and environmental conditions [76-78,93-95]. However, such a relationship between the parameters cannot be claimed in the accessions; for example, KMS441 contained a lower total amount of phenolic compounds but showed significantly higher values of antioxidant properties. The absence of correlation between phenolic compounds and antioxidant potential indicates that phytochemicals other than phenolic compounds could contribute to the antioxidant potential of the M. sacchariflorus accessions. Moreover, it appears that antioxidant properties depend more upon the concentration, composition, and synergistic effects of the phenolic compounds present in M. sacchariflorus accessions. This finding corroborates the observations of Mokrani and Madani [96], who observed synergistic or additive effects between phenolic compounds and increasing antioxidant activities in plants. Further study is necessary to determine if these compounds act individually, synergistically, or antagonistically.

Pearson correlation analysis showed a high, positive, and moderate correlation between altitude and phenolic compound contents in the accessions, indicating that variation in the degree of cold stress at different altitudes played a significant role in the accumulation of phenolic compounds in the plants. Moreover, previous studies have documented wide variation in the accumulation of phenolic compounds under the cold acclimation of plants [97-102]. In addition to intrinsic antioxidative properties, derivatives of ferulic acid improved the energy metabolism and increased the oxidative stress during cold stress acclimation [89,103]. In another study, an increased quantity of enzymes and genetic activity in flavonoid biosynthesis was observed during cold stress [104-107]. This trend was also reflected in the report of Wang et al. [108], who found that during the cold acclimation, phenolic compounds, such as flavonoids, act as antioxidants to scavenge ROS and prevent the possible injury of cell membranes. Moreover, Agati et al. [109] and Steponkus [110] observed an increased concentration of flavonoids in cellular organelles such as the chloroplasts, nucleus, and vacuoles, which increased cold resistance by stabilizing proteins and preventing aggregation in the membrane during cold acclimation [102,111-115].

Some have argued that plants growing in extremely cold environmental conditions developed strong antioxidant properties to scavenge ROS [116]. In the present study, phenolic compounds such as caffeic acid, protocatechuic acid, gentisic acid, $p$-hydroxybenzoic acid, $p$-coumaric acid, ferulic acid, kaempferol, and apigenin were remarkably higher in the Russian accessions as compared to the other accessions. It is likely that $M$. sacchariflorus growing in the extremely cold environmental conditions of the Russian region might have developed strong antioxidant capacities by accumulating more phenolic compounds to scavenge ROS. Moreover, in a similar study, higher concentrations of antioxidative compounds documented in plants grown under extremely cold conditions [117-119]. Low temperatures have been reported to cause oxidative stress to cells and elevation of ROS formation in cells [120]. To survive ROS, plants accumulate larger amount of phenolic compounds, which are efficient antioxidants [121] and thus prevent oxidative damage of plant cellular components and maintain membrane integrity [122,123]. Moreover, phenylalanine ammonia-lyase (PAL) activity (key enzymes in the biosynthesis of phenolic compounds) was increased during cold acclimation in Festulolium [124], triticale [125], winter rye [126]. Higher deposition of these compounds is important for cell energy metabolism, as phenolic compounds are useful for generating energy essential for the survival of cells [127]. Moreover, accumulation of these compounds in the cells helps to reduce the freezing temperature of the cellular components, thus improving the plant's resistance to extreme cold [128]. Gołębiowska-Pikania et al. [129] observed an increase in the concentrations of potentially antioxidant compounds such as $p$-hydroxybenzoic acid, chlorogenic acid, trans-cinnamic acid, and syringic acid in Microdochium nivale due to low temperatures, indicating that 
phenolic compounds significantly contribute to the survival and antioxidant properties of $M$. sacchariflorus accessions. Close associations have been observed between phenolic compounds and antioxidant potential $[130,131]$, and these parameters were influenced by variation in the plant's origin, its climatic conditions, its environment, altitudinal variation, and the duration of plant maturity $[130,132,133]$. This underlines the importance of the relationship between phenolic compound composition and antioxidant properties, which contribute vastly to the overwintering and cold stress tolerance of $M$. sacchariflorus. The composition and content of phenolic compounds could also be dependent on the morphological traits of the accessions. However, in the present study, the possibility of a link between phenolic compound composition and morphological traits has not been assessed; more research is needed to unveil this association in future studies.

\section{Conclusions}

This study constitutes the first report of the morphological traits, antioxidant activities, and phenolic compound profile of 32 accessions of M. sacchariflorus from four different countries. The results reveal significant variation in the studied parameters, supporting the notion that morphological traits, antioxidant properties, and the phenolic compound profiles of $M$. sacchariflorus are affected by geographical origin and by genetic factors. LCMS/MS analysis showed the presence of 22 phenolic compounds, which were remarkably varied within the $M$. sacchariflorus accessions. The study also revealed significant variation in the antioxidant potential of the accessions to scavenge DPPH and ABTS radicals. Our results suggest that phenolic compounds present in the M. sacchariflorus accessions may contribute significantly to their antioxidant capacity. Pearson's correlation analysis revealed a wide range of variation in the correlation co-efficient between these parameters, indicating that phenolic compounds present in the accessions played significant roles in the scavenging of radicals. This study provides scientific information about the phenolic compound profile and antioxidant properties of accessions from four different countries, and constitutes baseline data for breeders and researchers working in the fields of bioenergy crop development and bio fuel production. Despite great variation in morphological traits and chemical and antioxidant activity, some interesting correlations were found. The present results revealed the need of using both morphological and chemical markers for exploiting M. sacchariflorus accession biodiversity. Improved accession with useful traits and phytochemical and higher biological activity is a great interest for the possibility of increasing biomass production.

Supplementary Materials: The following are available online at https:/ /www.mdpi.com/2073-439 5/11/2/243/s1, Table S1: Pearson's correlation coefficients between the antioxidant potential and phenolic compounds in M. sacchariflorus accessions.

Author Contributions: B.K.G. contributed by performing the experiments and writing the manuscript. C.Y.Y. and E.J.S. supervised the experiment. S.H.K. and I.M.C. contributed by analyzing phenolic compounds and editing the manuscript. All authors have read and agreed to the published version of the manuscript.

Funding: This research received no external funding.

Institutional Review Board Statement: Not applicable.

Informed Consent Statement: Not applicable.

Data Availability Statement: Not applicable.

Acknowledgments: This work was supported by funding from the KU research professor program. This work was supported by a BK21 FOUR (Fostering Outstanding Universities for Research, grant No. 4220201013822, team: Crop Genetic Resources Research Team for Future Human Resources Development in Sustainable Premium Agricultural Industry, Konkuk University), the National Research Foundation of Korea, Republic of Korea.

Conflicts of Interest: The authors declare that they have no conflict of interest. 


\section{References}

1. Clifton-Brown, J.C.; Lewandowski, I. Overwintering problems of newly established Miscanthus plantations can be overcome by identifying genotypes with improved rhizome cold tolerance. New Phytol. 2000, 148, 287-294. [CrossRef]

2. Dwiyanti, M.S.; Stewart, J.R.; Yamada, T. Germplasm resources of Miscanthus and their application in breeding. In Bioenergy Feedstocks: Breeding and Genetics; Saha, M.C., Bhandari, H.S., Bouton, J.H., Eds.; John Wiley \&Sons: Oxford, UK, 2013 ; pp. 49-66.

3. Sacks, E.J.; Juvik, J.A.; Lin, Q.; Stewart, J.R.; Yamada, T. The gene pool of Miscanthus species and its improvement. In Genomics of the Saccharinae; Paterson, A.H., Ed.; Springer: New York, NY, USA, 2013; pp. 73-101.

4. Atkinson, C. Establishing perennial grass energy crops in the UK: A review of current propagation options for Miscanthus. Biomass Bioenergy 2009, 33, 752-759. [CrossRef]

5. Yook, M.J.; Lim, S.H.; Song, J.S.; Kim, J.W.; Zhang, C.J.; Lee, E.J.; Ibaragi, Y.; Lee, G.J.; Nah, G.; Kim, D.S. Assessment of genetic diversity of Korean Miscanthus using morphological traits and SSR markers. Biomass Bioenergy 2014, 66, 81-92. [CrossRef]

6. Clark, L.V.; Dzyubenko, E.; Dzyubenko, N.; Bagmet, L.; Sabitov, A.; Chebukin, P.; Johnson, D.A.; Kjeldsen, J.B.; Petersen, K.K.; Jørgensen, U. Ecological characteristics and in situ genetic associations for yield-component traits of wild Miscanthus from eastern Russia. Ann. Bot. 2016, 118, 941-955. [CrossRef]

7. Lewandowski, I.; Clifton-Brown, J.C.; Andersson, B.; Basch, G.; Christian, D.; Jørgensen, U.; Jones, M.; Riche, A.B.; Schwarz, K.U.; Tayebi, K.; et al. Environment and harvest time affects the combustion qualities of Miscanthus genotypes. Agron. J. 2003, 95, 1274-1280. [CrossRef]

8. Clifton-Brown, J.C.; Chiang, Y.C.; Hodkinson, T.R. Miscanthus: Genetic resources and breeding potential to enhance bioenergy production. In Genetic Improvement of Bioenergy Crops; Vermerris, W., Ed.; Springer Science: New York, NY, USA, 2008; pp. 273-294.

9. Lewandowski, I.; Clifton-Brown, J.C.; Scurlock, J.M.O.; Huisman, W. Miscanthus: European experience with a novel energy crop. Biomass Bioenergy 2000, 19, 209-227. [CrossRef]

10. Clifton-Brown, J.C.; Lewandowski, I.; Andersson, B.; Basch, G.; Christian, D.G.; Kjeldsen, J.B.; Jørgensen, U.; Mortensen, J.V.; Riche, A.B.; Schwarz, K.U.; et al. Performance of 15 Miscanthus Genotypes at Five Sites in Europe. J. Agron. J. 2001, 93, 1013-1019. [CrossRef]

11. Hirayoshi, I.; Nishikawa, K.; Kubono, M.; Murase, T. Cytogenetical studies on forage plants (VI). On the chromosome number of ogi (Miscanthus sacchariflorus). Res. Bull. Fac. Agric. Gifu Univ. 1957, 8, 8-13.

12. Lee, Y. Taxonomic studies on the genus Miscanthus: Relationships among the section, subsection, and species, part 2: Enumeration of species and varieties. J. Jpn. Bot. 1964, 39, 257-265.

13. Sun, Q.; Lin, Q.; Yi, Z.L.; Yang, Z.R.; Zhou, F.S. A taxonomic revision of Miscanthus s.l. (Poaceae) from China. Bot. J. Linn. Soc. 2010, 164, 178-220. [CrossRef]

14. Young, R.A. Processing of agro-based resources into pulp and paper. In Paper and Composites from Agro-Based Resources; Rowell, R.M., Young, R.A., Rowell, J.K., Eds.; CRC Press/Lewis Publishers: New York, NY, USA, 1997; pp. $137-245$.

15. Visser, P.; Pignatelli, V.; Jørgensen, U.; Oliveira, J.F.S. Utilisation of Miscanthus. In Miscanthus-For Energy and Fibre; Jones, M.B., Walsh, M., Eds.; James \& James: London, UK, 2001; pp. 109-154.

16. Park, H.J.; Oh, S.W.; Wen, M.Y. Manufacture and properties of Miscanthus-wood particle composite boards. J. Wood Sci. 2012, 58, 459-464. [CrossRef]

17. Liao, C.B.; Deng, Y.H.; Wang, X.Z.; Fan, X.L.; Yu, T.; Yang, Y. Manufacture and mechanical properties of biocomposite made of reed and silvergrass. Appl. Mech. Mater. 2013, 248, 237-242. [CrossRef]

18. Trinklein, D. Ornamental Grasses. In Plants of Wisconsin; Robert W. Freckmann Herbarium at University of Wisconsin-Stevens Point: Stevens Point, WI, USA; University of Missouri-Extension: Columbia, MO, USA, 2013.

19. Zub, H.W.; Brancourt-Hulmel, M. Agronomic and physiological performances of different species of Miscanthus a major energy crop. A review. Agron. Sustain. Dev. 2010, 30, 201-214. [CrossRef]

20. Tayot, X.; Chartier, M.; Varlet-Grancher, C.; Lemaire, G. Potential above-ground dry matter production of Miscanthus in northcentre France compared to sweet sorghum. In Biomass for Energy, Environment, Agriculture and Industry; Charter, P., Beenackers, A., Grassi, G., Eds.; Oxford Elsevier: Oxford, UK, 1995; pp. 556-564.

21. Heaton, E.A.; Dohleman, F.G.; Long, S.P. Meeting US bio-fuel goals with less land: The potential of Miscanthus. Glob. Chang. Biol. 2008, 14, 2000-2014. [CrossRef]

22. Cerutti, P.A. Peroxidant states and tumor promotion. Science 1985, 227, 375-381. [CrossRef] [PubMed]

23. Halliwell, B.; Gutteridge, J.C. Oxygen toxicity, radicals, transition metal and disease. Biochem. J. 1984, 319, 1-14. [CrossRef]

24. Finkel, T.; Holbrook, N.J. Oxidants, oxidative stress and the biology of ageing. Nature 2000, 408, 239-247. [CrossRef] [PubMed]

25. Young, I.S.; Woodside, J.V. Antioxidants in health and disease. J. Clin. Pathol. 2001, 54, 176-186. [CrossRef]

26. Ou, B.; Hampsch-Woodill, M.; Flanagan, J.; Deemer, E.K.; Prior, R.L.; Huang, D. Novel fluorometric assay for hydroxyl radical prevention capacity using fluorescein as the probe. J. Agric. Food Chem. 2002, 50, 2772-2777. [CrossRef]

27. Embuscado, M.E. Spices and herbs: Natural sources of antioxidants-A mini review. J. Funct. Foods 2015, 18, 811-819. [CrossRef]

28. Taghvaei, M.; Jafari, S.M. Application and stability of natural antioxidants in edible oils in order to substitute synthetic additives. J. Food Sci. Technol. 2015, 52, 1272-1282. [CrossRef] [PubMed]

29. Assefa, A.D.; Jeong, Y.J.; Kim, D.J.; Jeon, Y.A.; Lee, J.R.; Ko, H.C.; Baek, H.J.; Sung, J.S. Assessing phenolic content and antioxidant potential diversity in Allium plants using multivariate data analysis. Hortic. Environ. Biotechnol. 2018, 59, 759-773. [CrossRef] 
30. Mathew, S.; Abraham, E.T. Studies on the antioxidant activities of cinnamon (Cinnamonum verum) bank extracts, through various in vitro models. Food Chem. 2006, 94, 520-528. [CrossRef]

31. Sikora, E.; Cieslik, E.; Topolska, K. The source of natural antioxidants. Acta Sci. Pol. Technol. Aliment. 2008, 7, 5-17.

32. Yanishlieva-Maslarova, N.V.; Heinonen, I.M. Sources of natural antioxidants: Vegetables, fruits, herbs, spices and teas. In Antioxidants in Food, Practical Applications; Pokorny, J., Yanishlieva, N., Gordon, M., Eds.; Woodhead Publishing: Cambridge, UK, 2001; pp. 210-266.

33. Khanizadeh, S.; Tsao, R.; Rekika, D.; Yang, R.; Charles, M.T.; Rupasinghe, H.V. Polyphenol composition and total antioxidant capacity of selected apple genotypes for processing. J. Food Compos. Anal. 2008, 21, 396-401. [CrossRef]

34. Rebey, I.B.; Wannes, W.A.; Kaab, S.B.; Bourgou, S.; Tounsi, M.S.; Ksouri, R.; Fauconnier, M.L. Bioactive compounds and antioxidant activity of Pimpinella anisum L. accessions at different ripening stages. Sci. Hortic. 2019, 246, 453-461. [CrossRef]

35. Klinke, H.B.; Thomsen, A.B.; Ahring, B.K. Inhibition of ethanol-producing yeast and bacteria by degradation products produced during pre-treatment of biomass. Appl. Microbiol. Biotechnol. 2004, 66, 10-26. [CrossRef] [PubMed]

36. Scebba, F.; Sebustiani, L.; Vitagliano, C. Protective enzymes against activated oxygen species in wheat (Triticum aestivum L.) seedlings: Responses to cold acclimation. J. Plant Physiol. 1999, 155, 762-768.

37. Shigeoka, S.; Ishikawa, T.; Tamoi, M.; Miyagawa, Y.; Takeda, T.; Yabuta, Y.; Yoshimura, K. Regulation and function of ascorbate peroxidase isoenzymes. J. Exp. Bot. 2002, 53, 1305-1319. [CrossRef] [PubMed]

38. Gołębiowska, G.; Wędzony, M.; Płażek, A. The responses of pro and antioxidative systems to cold-hardening and pathogenesis differs in triticale (x Triticosecale Wittm) seedlings susceptible or resistant to pink snow mould (Microdochium nivale Fr., Samuels \& Hallett). J. Phytopathol. 2011, 159, 19-27.

39. Hanifei, M.; Dehghani, H.; Choukan, R. The role of antioxidant enzymes and phenolic compounds in disease resistance to Fusarium oxysporum f. sp. Melonis race 1.2. Int. J. Agron. Plant Prod. 2013, 4, 1985-1996.

40. Ivanov, S.; Miteva, L.; Alexieva, V.; Karjin, H.; Karanov, E. Alterations in some oxidative parameters in susceptible and resistant wheat plants infected with Puccinia recondita f.sp. tritici. J. Plant Physiol. 2004, 162, 275-279. [CrossRef] [PubMed]

41. Kiraly, L.; Barna, B.; Kiraly, Z. Plant resistance to pathogen infection: Forms and mechanisms of innate and acquired resistance. J. Phytopathol. 2007, 155, 385-396. [CrossRef]

42. Kumar, M.; Yadav, V.; Tuteja, N.; Johri, A.K. Antioxidant enzyme activities in maize plants colonized with Piriformospora indica. Microbiology 2009, 155, 780-790. [CrossRef] [PubMed]

43. Płażek, A.; Hura, K.; Żur, I.; Niemczyk, E. Relationship between frost tolerance and cold-induced resistance of spring barley, meadow fescue and winter oilseed rape to fungal pathogens. J. Agron. Crop. Sci. 2003, 189, 333-340. [CrossRef]

44. Norman, P.E.; Tongoona, P.; Shanahan, P.E. Diversity of the morphological traits of yam (Dioscorea spp.) genotypes from Sierra Leone. J. Appl. Biosci. 2011, 45, 3045-3058.

45. Tamiru, M.; Becker, H.C.; Maass, B.L. Comparative analysis of morphological and farmers cognitive diversity in yam landraces (Dioscorea spp) from Sothern Ethiopia. Trop. Agric. Dev. 2011, 55, $28-43$.

46. Kearsey, M.J.; Pooni, H.S. The Genetical Analysis of Quantitative Traits; Chapman and Hall: London, UK, 1996 ; pp. 1-17.

47. Nybom, H. Comparison of different nuclear DNA markers for estimating intraspecific genetic diversity in plants. Mol. Ecol. 2004, 13, 1143-1155. [CrossRef]

48. Smith, J.S.C.; Smith, O.S. Fingerprinting crop varieties. In Advances in Agronomy; Donald, L.S., Ed.; Elsevier: Amsterdam, The Netherlands, 1992; pp. 85-140.

49. Ximenes, E.; Kim, Y.; Mosier, N.; Dien, B.; Ladisch, M. Inhibition of cellulases by phenols. Enzym. Microb. Technol. 2010, 46, 170-176. [CrossRef]

50. González-Bautista, E.; Santana-Morales, J.C.; Ríos-Fránquez, F.J.; Poggi-Varaldo, H.M.; Ramos-Valdivia, A.C.; Cristiani-Urbina, E.; Ponce-Noyola, T. Phenolic compounds inhibit cellulase and xylanase activities of Cellulomonas flavigena PR-22. During saccharification of sugarcane bagasse. Fuel 2017, 196, 32-35. [CrossRef]

51. Jeong, S.W.; Kwon, S.J.; Ryu, J.; Kim, J.B.; Ahn, J.W.; Kim, S.H.; Jo, Y.D.; Choi, H.I.; Im, S.B.; Kang, S.Y. Development of EST-SSR markers through de novo RNA sequencing and application for biomass productivity in kenaf (Hibiscus cannabinus L.). Genes Genom. 2017, 39, 1139-1156. [CrossRef]

52. Ghimire, B.K.; Yu, C.Y.; Kim, S.H.; Chung, I.M. Assessment of Diversity in the Accessions of Setaria italica L. Based on Phytochemical and Morphological Traits and ISSR Markers. Molecules 2019, 24, 1486. [CrossRef] [PubMed]

53. Chung, I.M.; Chelliah, R.; Oh, D.H.; Kim, S.H.; Yu, C.Y.; Ghimire, B.K. Tupistra nutans Wall. root extract, rich in phenolics, inhibits microbial growth and $\alpha$-glucosidase activity, while demonstrating strong antioxidant potential. Braz. J. Bot. 2019, 42, 383-397. [CrossRef]

54. Thakur, A.K.; Singh, K.H.; Singh, L.; Nanjundan, J.; Khan, Y.J.; Singh, D. Patterns of subspecies genetic diversity among oilseed Brassica rapa as revealed by agro-morphological traits and SSR markers. J. Plant Biochem. Biotechnol. 2017, 26, 282-292. [CrossRef]

55. Kaplan, F.; Kopka, J.; Haskell, D.W.; Zhao, W.; Schiller, K.C.; Gatzke, N.; Sung, D.Y.; Guy, C.L. Exploring the temperature-stress metabolome of Arabidopsis. Plant Physiol. 2004, 136, 4159-4168. [CrossRef]

56. Wulff-Zottele, C.; Gatzke, N.; Kopka, J.; Orellana, A.; Hoefgen, R.; Fisahn, J.; Hesse, H. Photosynthesis and metabolism interact during acclimation of Arabidopsis thaliana to high irradiance and sulphur depletion. Plantcell Environ. 2010, 33, 1974-1988. [CrossRef] 
57. Jankanpaa, H.J.; Mishra, Y.; Schr€oder, W.P.; Jansson, S. Metabolic profiling reveals metabolic shifts in Arabidopsis plants grown under different light conditions. Plant Cell Environ. 2012, 35, 1824-1836. [CrossRef]

58. Labra, M.; Miele, M.; Ledda, B.; Grassi, F.; Mazzei, M.; Sala, F. Morphological characterization, essential oil composition and DNA genotyping of Ocimum basilicum L. cultivars. Plant Sci. 2004, 167, 725-731. [CrossRef]

59. Zhang, K.; Fan, G.; Zhang, X.; Zhao, F.; Wei, W.; Du, G.; Feng, X.; Wang, X.; Feng, W.F.; Song, G.; et al. Identification of QTLs for 14 agronomically important traits in Setaria italica based on SNPs generated from high-throughput sequencing. G3 Gene Genom Genet 2017, 7, 1587-1594. [CrossRef]

60. Yan, J.; Chen, W.; Lou, F.; Ma, H.; Meng, A.; Liu, G.; Zhu, M.; Li, S.; Zhou, H.; Zhu, W.; et al. Variability and adaptability of Miscanthus species evaluated for energy crop domestication. GCB Bioenergy 2011, 4, 49-60. [CrossRef]

61. Stewart, J.R.; Toma, Y.; Fernandez, F.G.; Nishiwaki, A.; Yamada, T.; Bollero, G. The ecology and agronomy of Miscanthus sinensis, a species important to bioenergy crop development, in its native range in Japan: A review. Glob. Chang. Biol. Bioenergy 2009, 1, 126-153. [CrossRef]

62. Nishiwaki, A.; Mizuguti, A.; Kuwabara, S.; Toma, Y.; Ishigaki, G.; Miyashita, T.; Yamada, T.; Matuura, H.; Yamaguchi, S.; Rayburn, A.L.; et al. Discovery of natural Miscanthus (Poaceae) triploid plants in sympatric populations of Miscanthus sacchariflorus and Miscanthus sinensis in southern Japan. Am. J. Bot. 2011, 98, 154-159. [CrossRef] [PubMed]

63. Christian, D.; Haase, E.; Clifton-Brown, J.; Cosentino, S. Agronomy of Miscanthus. In Miscanthus for Energy and Fibre; Jones, M.B., Walsh, M., Eds.; James \& James: London, UK, 2000; pp. 21-45.

64. Riche, A.; Christian, D. Estimates of rhizome weight of Miscanthus with time and rooting depth compared to switchgrass. Asp. Appl. Biol. 2001, 65, 147-152.

65. Dalir, M.; Safarnejad, A. Morphological, Molecular and Phytochemical Variation in Some Thyme Genotypes. J. Med. Plants By-Prod. 2017, 1, 41-52.

66. Dai, J.; Mumper, R.J. Plant phenolics: Extraction, analysis and their antioxidant and anticancer properties. Molecules 2010, 15, 7313-7352. [CrossRef]

67. Lygin, A.; Upton, J.; Dohleman, F.G.; Juvik, O.J.; Olga, A.; Zabotina, O.A.; Widholm, J.M.; Lozovaya, V.V. Antioxidant activity and total phenolic compounds in extracts of selected grasses (Poaceae). Herba Pol. 2011, 55, 214-221.

68. Schäfer, J.; Sattler, M.; Iqbal, Y.; Lewandowski, I.; Bunzel, M. Characterization of Miscanthus cell wall polymers. Gcb Bioenergy 2019, 11, 191-205. [CrossRef]

69. Parveen, I.; Wilson, T.; Donnison, I.S.; Cookson, A.R.; Hauck, B.; Threadgill, M.D. Potential sources of high value chemicals from leaves, stems and flowers of Miscanthus sinensis 'Goliath' and Miscanthus Sacchariflorus. Phytochemistry 2013, 92, 160-167. [CrossRef]

70. Donno, D.; Cerutti, A.K.; Prgomet, I.; Mellano, M.G.; Beccaro, G.L. Foodomics for mulberry fruit (Morus spp.): Analytical fingerprint as antioxidants' and health properties' determination tool. Food Res. Int. 2015, 69, 179-188. [CrossRef]

71. Amarowicz, R.; Pegg, R.B.; Rahimi-Moghaddam, P.; Barl, B.; Weil, J.A. Free-radical scavenging capacity and antioxidant activity of selected plant species from the Canadian prairies. Food Chem. 2004, 84, 551-562. [CrossRef]

72. Balasundram, N.; Sundram, K.; Samman, S. Phenolic compounds in plants and agri-industrial by-products: Antioxidant activity occurrence, and potential uses. Food Chem. 2006, 99, 191-203. [CrossRef]

73. Zhang, H.Y.; Sun, Y.M.; Wang, X.L. Substituent effects on $\mathrm{OH}$ bond dissociation enthalpies and ionization potentials of catechols: A DFT study and its implications in the rational design of phenolic antioxidants and elucidation of structure-activity relationships for flavonoid antioxidants. Chem. Eur. 2003, 9, 502-508. [CrossRef] [PubMed]

74. Moghaddam, M.; Mehdizadeh, L. Variability of total phenolic, flavonoid and rosmarinic acid content among Iranian basil accessions. LWT Food Sci. Technol. 2015, 63, 535-540. [CrossRef]

75. Neuhouser, M.L. Flavonoids and cancer prevention: What is the evidence in humans? Pharm Biol. 2004, 42, 34-45. [CrossRef]

76. Karimi, A.; Hadian, A.; Farzaneh, M.; Khadivi-Khub, A. Phenotypic diversity and volatile composition of Iranian Artemisia dracunculus. Indust. Crop. Prod. 2015, 65, 315-323. [CrossRef]

77. Ghahremani-majd, H.; Dashti, F.; Dastan, D.; Mumivand, H.; Hadian, J.; Esna-Ashari, M. Antioxidant and antimicrobial activities of Iranian mooseer (Allium hirtifolium Boiss) populations. Hortic. Environ. Biotechnol. 2012, 53, 116-122. [CrossRef]

78. Faudale, M.; Viladomat, F.; Bastida, J.; Poli, F.; Codina, C. Antioxidant activity and phenolic composition of wild, edible, and medicinal fennel from different Mediterranean countries. J. Agric. Food Chem. 2008, 56, 1912-1920. [CrossRef]

79. Kamalakkannan, N.; Prince, P.S.M. Antihyperglycaemic and antioxidant effect of rutin, a polyphenolic flavonoid, in streptozotocininduced diabetic wistar rats. Basic Clin. Pharmacol. Toxicol. 2006, 98, 97-103. [CrossRef]

80. Kikuzaki, H.; Hisamoto, M.; Hirose, K.; Akiyama, K.; Taniguchi, H. Antioxidant properties of ferulic acid and its related compounds. J. Agric. Food Chem. 2002, 50, 2161-2168. [CrossRef]

81. De Cássia Yukari Nishimura, F.; de Almeida, A.C.; Ratti, B.A.; Ueda-Nakamura, T.; Nakamura, C.V.; Ximenes, V.F.; de Oliveira Silva, S. Antioxidant Effects of Quercetin and Naringenin Are Associated with Impaired Neutrophil Microbicidal Activity. Evid.-Based Complement. Altern. Med. 2013, 2013, 795916. [CrossRef]

82. Parhiz, H.; Roohbakhsh, A.; Soltani, F.; Rezaee, R.; Iranshahi, M. Antioxidant and anti-inflammatory properties of the citrus flavonoids hesperidin and hesperetin: An updated review of their molecular mechanisms and experimental models. Phytother. Res. 2015, 29, 323-331. [CrossRef] [PubMed]

83. Graf, E. Antioxidant potential of ferulic acid. Free. Radic. Biol. Med. 1992, 13, 435-448. [CrossRef] 
84. Kanski, J.; Aksenova, M.; Stoyanova, A.; Butterfield, D.A. Ferulic acid antioxidant protection against hydroxyl and peroxyl radical oxidation in synaptosomal and neuronal cell culture systems in vitro: Structure-activity studies. J. Nutr. Biochem. 2002, 13, 273-281. [CrossRef]

85. Lee, C.H.; Yang, L.; Xu, J.Z.; Yeung, S.Y.V.; Huang, Y.; Chen, Z.Y. Relative antioxidant activity of soybean isoflavones and their glycosides. Food Chem. 2005, 90, 735-741. [CrossRef]

86. Davies, M.J. The oxidative environment and protein damage. Biochim. Biophys. Acta 2005, 1703, 93-109. [CrossRef]

87. Karamac, M.; Kosinska, A.; Pegg, R.B. Comparison of radical-scavenging activities for selected phenolic acids. Pol. J. Food Nutr. Sci. 2005, 14, 165-170.

88. Velika, B.; Kron, I. Antioxidant properties of benzoic acid derivatives against superoxide Radical. Free Radic. Antioxid. 2012, 2, 62-67. [CrossRef]

89. Balcerek, M.; Rakk, I.; Majtkowska, G.; Majtkowski, W.; Blagojevic, D.P.; Grubor-Lajsic, G.N.; Spasic, M.B. Cold defence responses: The role of oxidative stress. Front. Biosci. 2011, 3, 416-427.

90. García, A.; Toledano, A.; Andrés, M.A.; Labidi, J. Study of the antioxidant capacity of Miscanthus sinensis lignins. Process. Biochem. 2010, 45, 935-940. [CrossRef]

91. Dorman, D.; Bachmayer, O.; Kosar, M.; Hiltunen, R. Antioxidant properties of aqueous extracts from selected lamiaceae species grown in Turkey. J. Agric. Food Chem. 2004, 52, 762-770. [CrossRef]

92. Li, H.B.; Wong, C.C.; Cheng, K.W.; Chen, F. Antioxidant properties in vitro and total phenolic contents in methanol extracts from medicinal plants. Food Sci. Technol. 2008, 41, 385-390. [CrossRef]

93. Petridis, A.; Therios, I.; Samouris, G. Genotypic variation of total phenol and oleuropein concentration and antioxidant activity of 11 Greek olive cultivars (Olea europaea L.). Hortscience 2012, 47, 339-342. [CrossRef]

94. Ben Salah, M.; Abdelmelek, H.; Abderraba, M. Study of phenolic composition and biological activities assessment of olive leaves from different varieties grown in Tunisia. Med. Chem. 2012, 2, 107-111. [CrossRef]

95. Fabbri, A.; Galaverna, G.; Ganino, T. Polyphenol composition of olive leaves with regard to cultivar, time of collection and shoot type. Acta Hortic. 2008, 791, 459-464. [CrossRef]

96. Mokrani, A.; Madani, K. Effect of solvent, time and temperature on the extraction of phenolic compounds and antioxidant capacity of peach (Prunus persica L.) fruit. Sep. Purif. 2016, 162, 68-76. [CrossRef]

97. Nakabayashi, R.; Yonekura-Sakakibara, K.; Urano, K.; Suzuki, M.; Yamada, Y.; Nishizawa, T.; Matsuda, F.; Kojima, M.; Sakakibara, H.; Shinozaki, K.; et al. Enhancement of oxidative and drought tolerance in Arabidopsis by over accumulation of antioxidant flavonoids. Plant J. 2014, 77, 367-379. [CrossRef]

98. Winkel-Shirley, B. Biosynthesis of flavonoids and effects of stress. Curr. Opin. Plant Biol. 2002, 5, 218-223. [CrossRef]

99. Becker, C.; Klaering, H.P.; Kroh, L.W.; Krumbein, A. Cool-cultivated red leaf lettuce accumulates cyanidin-3-O-(6"-O-malonyl)glucoside and caffeoylmalic acid. Food Chem. 2014, 146, 404-411. [CrossRef]

100. Bilger, W.; Rolland, M.; Nybakken, L. UV screening in higher plants induced by low temperature in the absence of UV-B radiation. Photochem. Photobiol. Sci. 2007, 6, 190-195. [CrossRef]

101. Korn, M.; Peterek, S.; Mock, H.P.; Heyer, A.G.; Hincha, D.K. Heterosis in the freezing tolerance, and sugar and flavonoid contents of crosses between Arabidopsis thaliana accessions of widely varying freezing tolerance. Plant Cell Environ. 2008, 31, 813-827. [CrossRef]

102. Schulz, E.; Tohge, T.; Zuther, E.; Fernie, A.R.; Hincha, D.K. Natural variation in flavonol and anthocyanin metabolism during cold acclimation in Arabidopsis thaliana accessions. Plant Cell Environ. 2015, 38, 1658-1672. [CrossRef] [PubMed]

103. Griggio, M.A. Thermogenic mechanisms in cold-acclimated animals. Braz. J. Med. Biol. Res. 1988, 21, 171-176. [PubMed]

104. Koehler, G.; Wilson, R.C.; Goodpaster, J.V.; Sønsteby, A.; Lai, X.; Witzmann, F.A.; You, J.-S.; Rohloff, J.; Randall, S.K.; Alsheikh, M. Proteomic study of low-temperature responses in strawberry cultivars (Fragaria x ananassa) that differ in cold tolerance. Plant Physiol. 2012, 59, 1787-1809. [CrossRef] [PubMed]

105. Crifo, T.; Puglisis, I.; Petrone, G.; Recupero, G.R.; Lo Piero, A.R. Expression analysis in response to low temperature stress in blood oranges: Implication of the flavonoid biosynthetic pathway. Gene 2011, 476, 1-9. [CrossRef]

106. Hannah, M.A.; Wiese, D.; Freund, S.; Fiehn, O.; Heyer, A.G.; Hincha, D.K. Natural genetic variation of freezing tolerance in Arabidopsis. Plant Physiol. 2006, 142, 98-112. [CrossRef]

107. Kaplan, F.; Kopka, J.; Sung, D.Y.; Zhao, W.; Popp, M.; Porat, R.; Guy, C.L. Transcript and metabolite profiling during cold acclimation of Arabidopsis reveals an intricate relationship of cold-regulated gene expression with modifications in metabolite content. Plant J. 2007, 50, 967-981. [CrossRef]

108. Wang, L.; Tu, Y.-C.; Lian, T.-W.; Hung, J.-T.; Yen, J.-H.; Wu, M.-J. Distinctive antioxidant and antiinflammatory effects of flavonols. J. Agric. Food Chem. 2006, 54, 9798-9804. [CrossRef]

109. Agati, G.; Azzarello, E.; Pollastri, S.; Tattini, M. Flavonoids as antioxidants in plants: Location and functional significance. Plant Sci. 2012, 196, 67-76. [CrossRef]

110. Steponkus, P.L. Role of the plasma membrane in freezing injury and cold acclimation. Annu. Rev. Plant Physiol. 1984, 35, 543-584. [CrossRef]

111. Artus, N.N.; Uemura, M.; Steponkus, P.L.; Gilmour, S.J.; Lin, C.; Thomashow, M.F. Constitutive expression of the cold-regulated Arabidopsis thaliana COR15a gene affects both chloroplast and protoplast freezing tolerance. Proc. Natl. Acad. Sci. USA 1996, 93, 13404-13409. [CrossRef] 
112. Thalhammer, A.; Bryant, G.; Sulpice, R.; Hincha, D.K. Disordered Cold Regulated 15 proteins protect chloroplast membranes during freezing through binding and folding, but do not stabilize chloroplast enzymes in vivo. Plant Physiol. 2014, 166, 190-201. [CrossRef] [PubMed]

113. Hamaguchi, T.; Ono, K.; Murase, A.; Yamada, M. Phenolic compounds prevent Alzheimer's pathology through different effects on the amyloid-beta aggregation pathway. Am. J. Pathol. 2009, 175, 2557-2565. [CrossRef] [PubMed]

114. Ono, K.; Li, L.; Takamura, Y.; Yoshiike, Y.; Zhu, L.; Han, F.; Mao, X.; Ikeda, T.; Takasaki, J.-I.; Nishijo, H.; et al. Phenolic compounds prevent amyloid $\beta$-protein oligomerization and synaptic dysfunction by site-specific binding. J. Biol. Chem. 2012, 287, 14631-14643. [CrossRef] [PubMed]

115. Wang, J.; Ho, L.; Zhao, W.; Ono, K.; Rosensweig, C.; Chen, L.; Humala, N.; Teplow, D.B.; Pasinetti, G.M. Grape-derived polyphenolics prevent a $\beta$ oligomerization and attenuate cognitive deterioration in a mouse model of Alzheimer's disease. J. Neurosci. 2008, 28, 6388-6392. [CrossRef] [PubMed]

116. Klochkova, T.A.; Kang, S.H.; Cho, G.Y.; Pueschel, C.M.; West, J.A.; Kim, G.H. Biology of a terrestrial green alga Chlorococcum sp. (Chlorococcales, Chlorophyta) collected from the Miruksazi stupa in Korea. Phycologia 2006, 45, 115-124. [CrossRef]

117. Nagano, M.; Matsui, K.; Uemura, M. Klebsormidium flaccidum, a charophycean green alga, exhibits cold acclimation that is closely associated with compatible solute accumulation and ultrastructural changes. Plant Cell Environ. 2008, 31, 872-885. [CrossRef]

118. Solecka, D.; Boudet, A.M.; Kacperska, A. Phenylpropanoid and anthocyanin changes in low-temperature treated winter oilseed rape leaves. Plant Physiol. Biochem. 1992, 37, 491-496. [CrossRef]

119. Han, J.W.; Lee, K.P.; Yoon, M.; Kang, S.H.; Kim, G.H. Cold stress regulation of a bi-functional 3-dehydroquinate dehydratase/shikimate dehydrogenase (DHQ/SDH)-like gene in the freshwater green alga Spirogyra varians. Bot. Mar. 2009, 52, 178-185. [CrossRef]

120. Zykova, V.V.; Grabel'nykh, O.I.; Turchaninova, V.V.; Antipina, A.I.; Koroleva, N.A.; Kolesnichenko, A.V.; Pobezhimova, T.P.; Konstantinov, Y.M.; Voinikov, V.K. The Effect of CSP310 on Lipid Peroxidation and Respiratory Activity in Winter Wheat Mitochondria. Russ. J. Plant Physiol. 2002, 49, 628-634. [CrossRef]

121. Rice-Evans, C.A.; Miller, N.J.; Paganga, G. Antioxidant Properties of Phenolic Compounds. Trends Plant Sci. 1997, 2, 152-159. [CrossRef]

122. Zhao, H.J.; Zou, Q. Protective Effects of Exogenous Antioxidants and Phenolic Compounds on Photosynthesis of Wheat Leaves under High Irradiance and Oxidative Stress. Photosynthetica 2002, 40, 523-527. [CrossRef]

123. Lin, C.M.; Chen, C.T.; Lee, H.H.; Lin, J.K. Prevention of Cellular ROS Damage by Isovitexin and Related Flavonoids. Planta Med. 2002, 68, 365-367. [CrossRef] [PubMed]

124. Pociecha, E.; Płażek, A.; Janowiak, F.; Zwierzykowski, Z. ABA level, proline and phenolic concentration, and PAL activity induced during cold acclimation in androgenic Festulolium forms with contrasting resistance to frost and pink snow mould (Microdochium nivale). Physiol. Mol. Plant Pathol. 2008, 73, 126-132. [CrossRef]

125. Dubas, E.; Gołębiowska, G.; Żur, I.; Wędzony, M. Microdochium nivale (Fr., Samuels \& Hallett): Cytological analysis of the infection process in triticale (x Triticosecale Wittm.). Acta Physiol. Plant. 2011, 33, 529-537.

126. Żur, I.; Dubas, E.; Pociecha, E.; Dubert, F.; Kolasińska, I.; Płażek, A. Cytological analysis of infection process and the first defence responses induced in winter rye (Secale cereale L.) seedlings inoculated with Microdochium nivale. Physiol. Mol. Plant Pathol. 2011, 76, 189-196. [CrossRef]

127. Janas, K.M.; Cvikrová, M.; Palagiewicz, A.; Szafranska, K.; Posmyk, M.M. Constitutive Elevated Accumulation of Phenylpropanoids in Soybean Roots at Low Temperature. Plant Sci. 2002, 163, 369-373. [CrossRef]

128. Chalker-Scott, L. Environmental Significance of Anthocyanins in Plant Stress Responses. Photochem. Photobiol. 1999, 70, 1-9. [CrossRef]

129. Gołębiowska-Pikania, G.; Dziurka, M.; Iwona Wąsek, I.; Wajdzik, K.; Dyda, M.; Wędzony, M. Changes in phenolic acid abundance involved in low temperature and Microdochium nivale (Samuels and Hallett) cross-tolerance in winter triticale ( $x$ Triticosecale Wittmack). Acta Physiol. Plant. 2019, 41, 38. [CrossRef]

130. Ghasemi, P.A.; Hashemi, M.; Taherian Ghahfarokhi, F. Essential oil and chemical compositions of wild and cultivated Thymus daenensis Celak and Thymus vulgaris L. Ind. Crops Prod. 2013, 48, 43-48. [CrossRef]

131. Gasch, A.P.; Spellman, P.T.; Kao, C.M.; Carmel-Harel, O.; Eisen, M.B.; Storz, G.; Saitou, N.; Nei, M. The neighbor-joining method: A new method for reconstructing phylogenetic trees. Mol. Biol. Evol. 1987, 4, 406-425.

132. Mediani, A.; Abas, F.; Khatib, A.; Ping, T.C.; Lajis, N.H. Influence of growth stage and season on the antioxidant constituents of Cosmos caudatus. Plant Food Hum. Nutr. 2012, 67, 344-350. [CrossRef] [PubMed]

133. Jugran, A.K.; Bahukhandi, A.; Dhyani, P.; Bhatt, I.D.; Rawal, R.S.; Nandi, S.K. Impact of Altitudes and Habitats on Valerenic Acid, Total Phenolics, Flavonoids, Tannins, and Antioxidant Activity of Valeriana jatamansi. Appl. Biochem. Biotechnol. 2016, 179, 911-926. [CrossRef] [PubMed] 